\title{
A target engagement assay to assess uptake, potency and retention of antibiotics in living bacteria
}

\section{Rebeka Fanti}

State University of Campinas

Stanley Vasconcelos

State University of Campinas

Carolina Catta-Preta

State University of Campinas

Jaryd Sullivan

McGill University https://orcid.org/0000-0002-6607-5078

Gustavo Riboldi

State University of Campinas

\section{Caio dos Reis}

State University of Campinas

\section{Priscila Ramos}

State University of Campinas

Aled M. Edwards

Structural Genomics Consortium

\section{Marcel Behr}

McGill University https://orcid.org/0000-0003-0402-4467

Rafael M. Couñago ( $\sim$ rafaelcounago@gmail.com )

State University of Campinas

\section{Research Article}

Keywords: Antimicrobials, DHFR, target engagement assay, BRET, structure-based drug discovery

Posted Date: July 12th, 2022

DOl: https://doi.org/10.21203/rs.3.rs-1188756/v2

License: (c) (1) This work is licensed under a Creative Commons Attribution 4.0 International License.

Read Full License 


\section{A target engagement assay to assess uptake, potency and retention of}

\section{antibiotics in living bacteria}

Rebeka C. Fanti ${ }^{1,2, *}$, Stanley N. S. Vasconcelos ${ }^{1, *}$, Carolina M. C. Catta-Preta ${ }^{1}$, Jaryd R. Sullivan ${ }^{3,4,5}$, Gustavo P. Riboldi ${ }^{1}$, Caio V. dos Reis ${ }^{1}$, Priscila Z. Ramos ${ }^{1}$, Aled M. Edwards ${ }^{6}$, Marcel A. Behr ${ }^{3,4,5,7}$ and Rafael M. Couñago ${ }^{1,2, *}$

1 - Centro de Química Medicinal (CQMED), Centro de Biologia Molecular e Engenharia Genética (CBMEG), Universidade Estadual de Campinas (UNICAMP), Campinas, Brazil, 13083-886

2 - Post-Graduate Program in Genetics and Molecular Biology (PGBM), UNICAMP, Campinas, Brazil, 13083970

3 - Department of Microbiology \& Immunology, McGill University, Montréal, Canada, H3A 2B4

4 - Infectious Diseases and Immunity in Global Health Program, Research Institute of the McGill University Health Centre, Montréal, Canada, H3A 2B4

5 - McGill International TB Centre, Montréal, Canada, H3G 1A4

6 - Structural Genomics Consortium, 101 College Street, Toronto, Canada, M5G 1L7

7 - Department of Medicine, McGill University Health Centre, Montréal, Canada, H4A 3J1

*Corresponding author: rafaelcounago@gmail.com

$¥$ Contributed equally 


\section{Abstract}

New antibiotics are urgently needed to counter the emergence of antimicrobial resistant pathogenic bacteria. A major challenge in antibiotics drug discovery is to turn potent biochemical inhibitors of essential bacterial components into effective antimicrobials. This difficulty is underpinned by a lack of methods to investigate the physicochemical properties needed for candidate antibiotics to permeate the bacterial cell envelope and avoid clearance by the action of bacterial efflux pumps. To address these issues, here we used a target engagement assay to measure the equilibrium and kinetics binding parameters of antibiotics targeting dihydrofolate reductase (DHFR) in live bacteria. We also used this assay to identify novel DHFR ligands having antimicrobial activity from a library of compounds. We validated this approach using the Gram-negative bacteria Escherichia coli and the emerging human pathogen Mycobacterium abscessus. We expect the use of target engagement assays in bacteria to expedite the discovery and progression of novel, cell-permeable antibiotics with on-target activity.

\section{Keywords:}

Antimicrobials, DHFR, target engagement assay, BRET, structure-based drug discovery

Most antimicrobials act by potently inactivating essential enzymes residing within the bacterial cytoplasm, but the optimal characteristics of an antibiotic extend far beyond biochemical potency. The outer membranes of Gram-negative and Mycobacteria, and, to a lesser extent, the cell wall of Gram-positive bacteria function as permeability barriers to solutes, and represent major obstacles for antibiotics to enter bacterial cells ${ }^{1-3}$. Further, to accumulate at effective concentrations, antimicrobials must gain access to the bacterial cytoplasm faster than they are forced out by efflux pumps ${ }^{4}$. Finally, antibiotics must also withstand the action of bacterial antibiotic-modifying enzymes ${ }^{5}$. After decades of efforts from both academia and industry, it is now clear that finding compounds that can perform all these tasks, and that are also safe for the human host, is far from trivial ${ }^{6-8}$. Consequently, the emergence of antimicrobial resistance greatly outpaces our current capacity to discover, develop and approve new antimicrobials, especially those targeting Gram-negative and Mycobacterial pathogens ${ }^{9}$.

The two main strategies to identify and progress new antimicrobials have complementary weaknesses ${ }^{6-}$ 8. Approaches that screen for biochemical inhibitors of purified components too often identify compounds whose in vitro potency correlates poorly with cellular activity. Approaches that use whole cell assays to identify biologically active hits too often yield compounds for which it is difficult to ascertain their mechanism of action, severely impairing compound prioritization and progression. Target deconvolution 
of whole cell active compounds can alleviate some of these drawbacks ${ }^{10}$. Nevertheless, it is clear that new strategies are needed that can merge target-based and whole-cell approaches and generate druglike chemical starting points with both on-target and in-cell activity. An example of such a strategy are chemical-genetics approaches that combine collections of hypomorph mutant strains and chemical screening to identify biologically-active compounds and establish their mechanism of action ${ }^{11}$. Although powerful, chemical-genetics approaches require the creation and extensive characterization of hundreds of hypomorph mutants and are limited to bacteria amenable to high-throughput genetic manipulations. The development of similar strategies that are less labor-intensive and costly, and that can be more easily applied to various bacteria, would make identifying new chemical starting points for validated and novel targets more accessible to the broader scientific community.

In addition to the formidable obstacles imposed by the bacterial cell envelop and efflux pumps, antimicrobial drug discovery also suffers from an incomplete understanding of how changes in the physicochemical properties of a compound affect its entry and retention in bacterial cells ${ }^{12-17}$. Advances in this area could lead to the design of more effective antibiotics and of chemical libraries better suited for antimicrobial discovery. For example, mass spectrometry-based methods have been used to investigate compound entry rules and turn narrow-spectrum antibiotics into compounds having activity against both Gram-positive and Gram-negative bacteria 12,18,19. Nevertheless, the use of mass spectrometry to investigate compound accumulation in bacteria requires intensive sample manipulation and precludes the use of living cells ${ }^{12}$. Thus, it is clear that new methods are also required that can directly assess compound entry and retention times in living bacterial cells.

In recent years, the use of assays based on bioluminescence resonance energy transfer (BRET) has found wide application in assessing target-drug interactions in mammalian cells. These studies employ matched pairs of BRET donors and acceptors that have overlapping emission/absorption spectra. The BRET donor is usually an engineered version of the target protein fused to a luciferase, whereas the acceptor is a modified version of a known target ligand containing a luciferase-compatible fluorophore. When BRET donor and acceptor are within $\sim 50 \AA$ of one another, the energy from the luciferase reaction is transferred to the acceptor fluorophore, which, in turn, emits fluorescence at a different wavelength. This BRET response is commonly reported as the ratio between acceptor and donor signals, facilitating quantification and mitigating potential artifacts due to, for example, variations in donor expression levels between samples or in luciferase substrate concentration ${ }^{20,21}$. Additionally, BRET-based assays are generally preferred over those based on fluorescence due to their increased sensitivities in microplate 
formats ${ }^{20-22}$. Unmodified compounds that displace the acceptor molecule from the luciferase-fused target protein disrupt energy transfer, enabling real-time analysis of compound binding and dissociation 23,24. As such, in-cell BRET-based target engagement assays can yield equilibrium and kinetic binding parameters of unmodified compounds to their molecular targets within live cells under physiologicallyrelevant conditions ${ }^{24-26}$. Equivalent parameters obtained in vitro with purified components, such as the equilibrium dissociation constant $\left(K_{\mathrm{d}}\right)$ and the dissociation rate constant $\left(k_{\text {off }}\right)$, are familiar to medicinal chemists and often used to explore structure-activity relationships aimed at improving the biochemical potencies and on-target residence times of test compounds ${ }^{27}$. In-cell target engagement assays require minimal sample manipulation and are routinely used in medicinal chemistry programs to develop cellpermeable ligands with on-target activity in human-derived cells ${ }^{24,28}$, but their use in antimicrobial drug discovery has not yet been explored. Development of cell-based target engagement assays for both validated and novel targets of antimicrobials would likely accelerate the discovery and progression of cellpermeable compounds with on-target biological activity by allowing compound progression via exploration of structure-activity relationships.

Here we describe the development of a BRET-based assay for a validated antimicrobial target, the dihydrofolate reductase enzyme (DHFR) ${ }^{29}$. We show this assay combines the strengths of both targetbased and whole-cell strategies, allowing target engagement of unmodified compounds to be assessed directly in cultures of live bacteria. We used this assay to obtain equilibrium and kinetic parameters for the interaction of DHFR and its ligands in cultures of live Escherichia coli, a Gram-negative bacterium, and Mycobacterium abscessus, an emerging human pathogen ${ }^{30}$. We also used this assay to identify novel, cell-permeable DHFR ligands from whole cell phenotypic screens in E. coli.

\section{Results \& Discussion}

Development of a novel target engagement assay in bacteria. BRET-based target engagement (TE) assays rely on the ability of unmodified test compounds to competitively displace a fluorescent probe, the BRET acceptor, from the luciferase-fused target protein, the BRET donor, within whole cells. To demonstrate BRET-based TE assays can be used in bacteria, we developed a matched pair of BRET acceptor and donor based on the antibiotic trimethoprim (TMP) and its validated molecular target, the bacterial enzyme dihydrofolate reductase (DHFR). DHFR employs a co-factor, NADPH, to catalyze the reduction of 7,8dihydrofolate (diHF) to 5,6,7,8-tetrahydrofolate (THF), which is an essential component in the synthesis of purines, pyrimidines, and several amino acids in bacteria. TMP is a reversible DHFR inhibitor that blocks the enzyme folate-biding site, hampering DNA synthesis and causing growth arrest in bacteria ${ }^{29,31,32}$. 
To turn E. coli (Eco)DHFR into a BRET donor, we fused this enzyme to the C-terminus of NanoLuc (NLuc) via a short, flexible linker (Fig 1a). NLuc is a genetically-engineered version of a small luciferase subunit (19.1 kDa) from a deep-sea shrimp with improved biochemical and light emission properties ${ }^{33}$. To function as a BRET donor in our assay, the fusion protein (hereafter called NLuc-EcoDHFR) must retain both the NLuc ability to generate blue light in the presence of its substrate furimazine ${ }^{33}$, and the EcoDHFR ability to reversibly bind folate-competitive ligands, such as TMP, which will serve as the scaffold for the BRET acceptor (see below). To better characterize the fusion protein, we produced recombinant NLuc-EcoDHFR in E. coli cells (Supplementary Fig. 1). We showed that addition of NLuc substrate to the purified fusion protein in vitro resulted in the robust emission of blue light $(\sim 450 \mathrm{~nm})$. Further, NLuc-EcoDHFR-generated luminescence was almost completely extinguished by the addition of a commercially-available NLuc inhibitor ${ }^{34}$ to the reaction mixture (Fig. 1b). These results confirmed the fusion protein retained NLuc activity in vitro. 
Figure 1

a

\section{BRET donor}

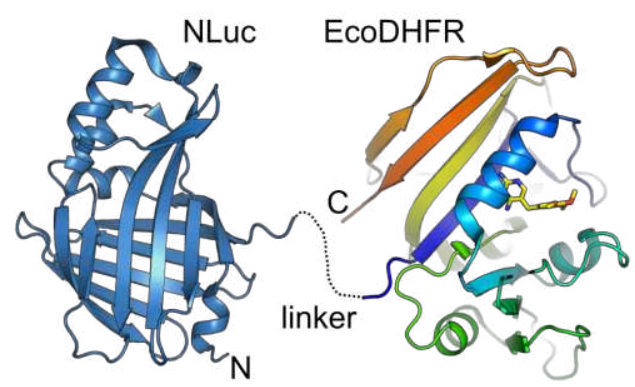

C DHFR activity in vitro

NLuc-EcoDHFR $K_{\mathrm{M}, \mathrm{diHF}}=9.0 \mu \mathrm{M}(\mathrm{Cl} 95 \%: 6.1-13.0)$

$\Delta-$ EcoDHFR $K_{\mathrm{M}, \mathrm{diHF}}=7.3 \mu \mathrm{M}(\mathrm{Cl} 95 \%: 5.0-10.0)$

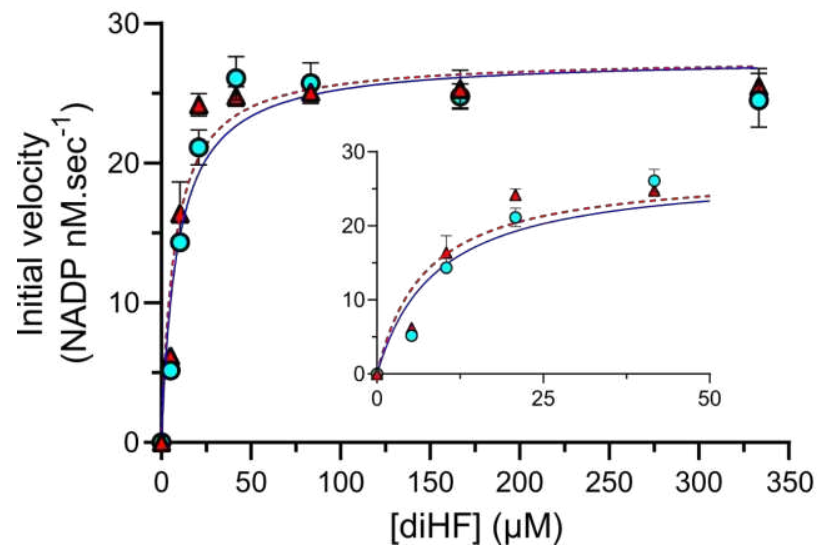

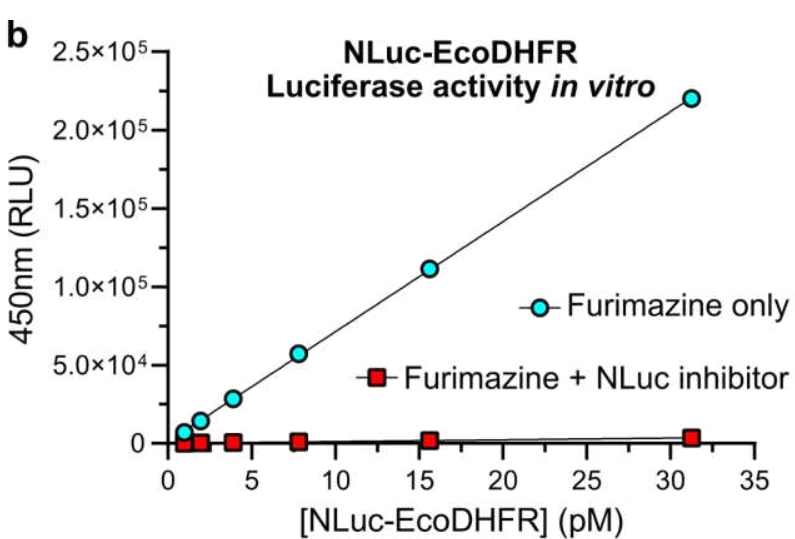

d TMP DHFR inhibition in vitro NLuc-EcoDHFR $K_{\mathrm{i}}=138.3 \mathrm{pM}$ (Cl 95\%: 119.5-159.9)

$\triangle-$ ECODHFR $_{\mathrm{i}}=129.0 \mathrm{pM}(\mathrm{Cl} 95 \%$ : 113.6-146.4)

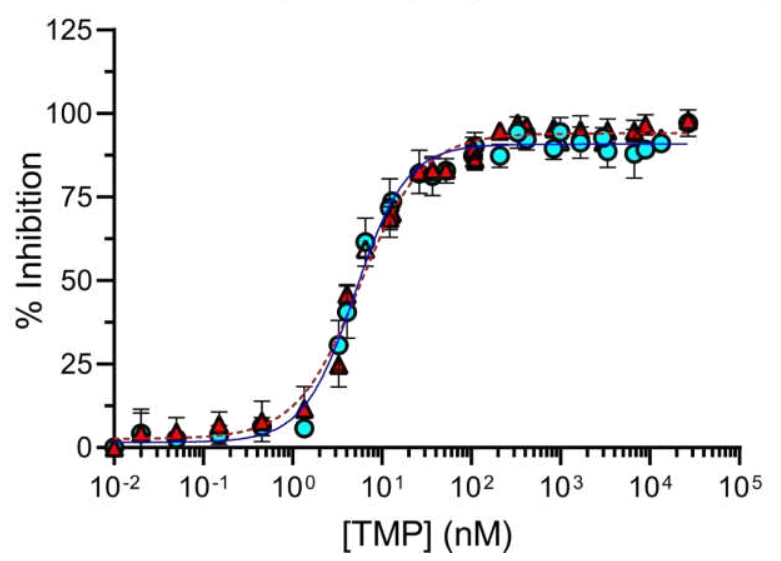

Figure 1 - Design and characterization of BRET donor NLuc-EcoDHFR in vitro. a Design strategy for fusing NLuc (blue cartoon, PDB ID 5IBO) to the N-terminal of EcoDHFR (cartoon, colored in a gradient from blue - N-terminal; to orange - C-terminal, PDB ID: 6XG5). Dotted line indicates a 9-amino acid-long linker region. $\mathrm{N}$ - and $\mathrm{C}$-termini for the fusion protein are indicated. $\mathbf{b}$ NLuc-EcoDHFR retains luciferase activity in vitro. Light emissions at $450 \mathrm{~nm}$ (in relative light units - RLU) produced by increasing concentrations of purified NLuc-EcoDHFR supplemented with NLuc substrate furimazine in the absence (cyan circles) or presence (red squares) of a commercially-available NLuc inhibitor. Solid black lines indicate linear regression fitting of experimental points (mean \pm SEM of a representative experiment performed in duplicates). c NLucEcoDHFR retains EcoDHFR enzymatic activity in vitro. Determination of kinetic parameters for NLucEcoDHFR (cyan circles) and EcoDHFR (red triangles). Non-linear fitting of experimental data points (mean \pm SEM for a representative experiment performed in triplicates) to the Michaelis-Menten kinetics model is shown for the wild-type (dotted red line) and NLuc-fused EcoDHFR (solid blue line). Inset shows data and fitting at low diHF concentrations. $\mathbf{d}$ TMP inhibits both EcoDHFR and NLuc-EcoDHFR equipotently. Determination of TMP inhibitory constant $\left(K_{\mathrm{i}}\right)$ for wild-type (red triangles) and NLuc-fused EcoDHFR (cyan cirlces). $K_{\mathrm{i}}$ values shown were obtained using the Cheng-Prusoff formalism following non-linear fitting of 
experimental data points (mean \pm SEM of two independent experiments performed in triplicates) to a four-parameter dose-response curve (EcoDHFR: dotted red line; NLuc-EcoDHFR: solid blue line).

We next showed the fusion protein also retained wild-type EcoDHFR activity in vitro using a fluorescencebased assay that monitors the enzyme-catalyzed oxidation of NADPH in the presence of the DHFR substrate diHF. Our results indicated that both NLuc-EcoDHFR and wild-type EcoDHFR proteins had comparable Michaelis-Menten constants for diHF and maximal reaction velocities in vitro (Fig. 1c). We used this same assay to obtain enzyme inhibition constants $\left(K_{\mathrm{i}}\right)$ for TMP and methotrexate (MTX), a chemically-distinct DHFR inhibitor that also competes for the enzyme folate-binding site (Supplementary Fig. 2a) ${ }^{29}$. Our data indicated that both DHFR inhibitors were equipotent towards wild-type and NLucEcoDHFR (Fig. 1d, Supplementary Fig. 2b). These results confirmed the fusion protein retained wild-type EcoDHFR enzymatic properties and susceptibility levels to folate-competitive ligands in vitro.

We followed up these in vitro experiments with equivalent ones in the Gram-negative bacteria E. coli. To show NLuc-EcoDHFR had luciferase activity in bacteria, we added NLuc substrate directly to medium containing $E$. coli cells ectopically expressing the fusion protein. Our results indicated these cells emitted light at the expected wavelength ( $450 \mathrm{~nm})$, whereas no equivalent luminescence was detected from cultures of $E$. coli cells ectopically expressing wild-type EcoDHFR alone (Fig. 2a, conditions 1 and 3). As NLuc is a very bright luciferase, light emitted by fusion protein extravasated to the medium would likely decrease assay accuracy and robustness. To address this issue, we once again used the commerciallyavailable NLuc inhibitor shown effective in vitro against purified NLuc-EcoDHFR (Fig. 1b). This NLuc inhibitor was originally developed to not permeate mammalian cells ${ }^{34}$, and our results indicated it was also poorly permeable to bacteria (Fig 2a). First, addition of the extracellular NLuc inhibitor directly to medium containing $E$. coli expressing the fusion protein resulted in only a small decrease in luminescence, compared to the untreated control (Fig. 2a, condition 1). These results suggested that most of the observed luminescence originated from within bacteria. Further, we confirmed the effectiveness of the NLuc inhibitor in bacterial culture medium by showing it could almost completely quench the activity of excess purified fusion protein added to medium containing cells expressing wild-type EcoDHFR (Fig. 2a, condition 2). Together, these results showed that commercially-available NLuc substrate and extracellular inhibitor can be successfully used in bacteria and both of these reagents were used in all subsequent cellbased BRET experiments. More importantly, our results indicated that the fusion protein retained NLuc 
activity in E. coli and that we could detect a robust luminescence signal from bacteria expressing NLucEcoDHFR.

Figure 2

a

Luciferase activity in E. coli cultures

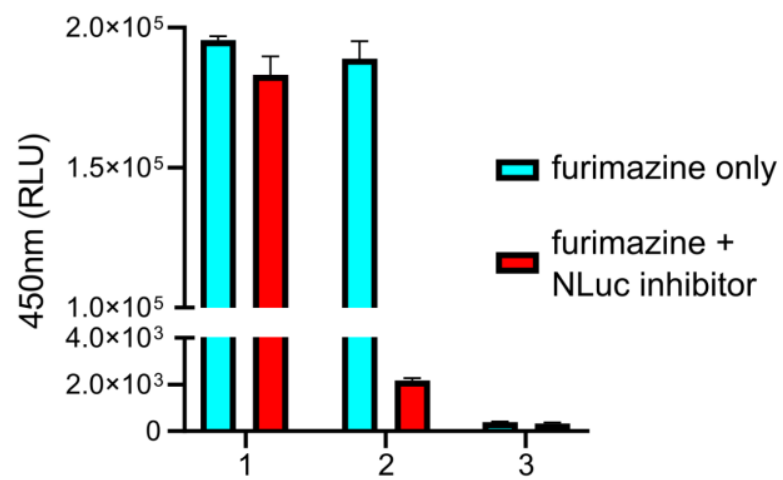

1 - Plasmid: NLuc-EcoDHFR

2 - Plasmid: EcoDHFR + purified NLuc-EcoDHFR

3 - Plasmid: EcoDHFR b

TMP MIC for E. coli (wild-type and NLuc-EcoDHFR)

wild-type MIC $=0.7 \mu \mathrm{M}(\mathrm{Cl} 95 \%$ : 0.6-0.8)

-o- NLuc-EcoDHFR MIC > $20.0 \mu \mathrm{M}$

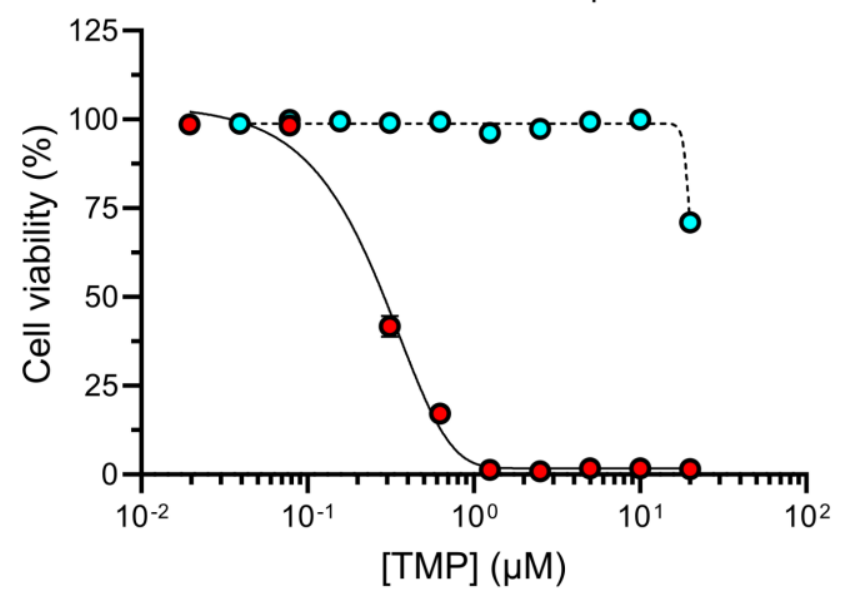

Figure 2 - The fusion protein retained NLuc and EcoDHFR activity in E. coli cells. a Detection of luminescence $(450 \mathrm{~nm})$ in cultures of $E$. coli BL21De3-R ${ }^{35}$ expressing the fusion protein (1) or wild-type EcoDHFR ( 2 and 3 ). Cell cultures in 2 were supplemented with purified fusion protein. Luminescence was measured in the presence (red bars) or absence (cyan bars) of a commercially-available extracellular NLuc inhibitor. Data shown are mean \pm SEM of a representative experiment performed in triplicates. $\mathbf{b}$ determination of TMP minimum inhibitory concentration (MIC) for wild-type $E$. coli with (cyan circles) or without (red circles) ectopic expression of the fusion protein. MIC values indicated were calculated by extrapolating a tangent from the inflexion point of a fitted Gompertz curve (solid line - wild-type; dotted line - strain expressing NLuc-EcoDHFR) to the no-growth line ${ }^{36}$. Data shown are mean \pm SEM of a representative experiment performed in triplicates (wild-type) or duplicates (strain expressing NLucEcoDHFR).

Next, we showed the fusion protein also retained EcoDHFR activity in bacteria. For that, we challenged $E$. coli expressing NLuc-EcoDHFR with increasing concentrations of TMP. Clinical isolates resistant to this antibiotic often overexpress DHFR ${ }^{37}$, and, accordingly, E. coli ectopically expressing the fusion protein were much less sensitive to TMP than wild-type (Fig. 2b). These results indicated that addition of NLuc did not greatly impair the DHFR activity of the fusion protein within live E. coli cells.

Having established that our BRET donor retained both NLuc and EcoDHFR functions in vitro and in bacteria, we turned our attention to the development of a cell-permeable BRET acceptor that could reversibly bind 
to EcoDHFR, and was compatible with NLuc-generated luminescence. TMP is a folate-competitive, reversible inhibitor of DHFR widely used in the clinic as an antimicrobial ${ }^{29}$. To turn this antibiotic into a BRET acceptor, we replaced the solvent-exposed para-methoxy group in TMP benzene ring with a short, PEG-based spacer attached to NanoBRET-590 SE, a bright, boron-dipyrromethene(BODIPY)-based, redfluorescent dye (hereafter we refer to this BRET acceptor as TMP-590) (Fig. 3a). Based on available structural information ${ }^{31,32}$, we expected the BRET probe to retain TMP ability to reversibly bind EcoDHFR, while keeping its fluorophore portion solvent-exposed and within the appropriate distance limits for efficient energy transfer ( $5 \mathrm{~nm}){ }^{38}$ (Fig. 3b). Likewise, we expected TMP-590 to retain the antibiotic ability to permeate $E$. coli, which is likely to happen through general porins - outer membrane proteins that form water-filled open channels and allow the free diffusion of small ( 600 Da or less) hydrophilic molecules ${ }^{39}$. To validate our BRET probe design strategy, we first characterized TMP-590 binding to purified NLucEcoDHFR in vitro. These experiments were performed in the presence of NLuc substrate and saturating concentrations of NADPH $(900 \mu \mathrm{M})$, a DHFR cofactor abundant in cells that increases the enzyme affinity for TMP > 100-fold ${ }^{40}$. Titration of the BRET probe to purified fusion protein ( $\sim 15 \mathrm{pM}$ ) resulted in a dosedependent increase of red-shifted luminescence at the expected wavelength $(620 \mathrm{~nm})$. The resulting data (reported here as the blank corrected BRET signal - the ratio between the recorded readings at acceptor, $620 \mathrm{~nm}$, and donor, $450 \mathrm{~nm}$, wavelengths) showed a characteristic saturation binding curve that allowed us to estimate an equilibrium dissociation constant $\left(K_{d}\right)$ of $28.5 \mathrm{nM}$ (Cl 95\%: 23.6-34.5) for this interaction (Fig. 3c). Further, competitive binding experiments showed that both TMP and MTX could displace TMP590 from purified NLuc-EcoDHFR. Titration of both DHFR inhibitors to purified NLuc-EcoDHFR in the presence of a fixed concentration of TMP-590 (100 nM) resulted in a dose-dependent reduction of BRET signal. These data allowed us to estimate equilibrium dissociation constants for TMP and MTX $\left(K_{\mathrm{dA}}\right)$ of 7.4 $\mathrm{nM}(95 \% \mathrm{Cl}: 7.0-8.0 \mathrm{nM})$ and $2.3 \mathrm{pM}(95 \% \mathrm{Cl}: 2.1-2.5 \mathrm{pM})$, respectively (Fig. 3d). Together, these results showed TMP-590 can function as a BRET acceptor for the luminescence generated by the fusion protein and that folate-competitive DHFR ligands can disrupt the interaction between TMP-590 and NLucEcoDHFR in vitro. 
Figure 3

a

BRET acceptor TMP-590

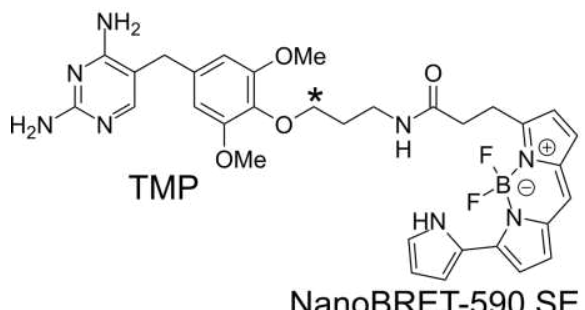

C

NanoBRET-590 SE b

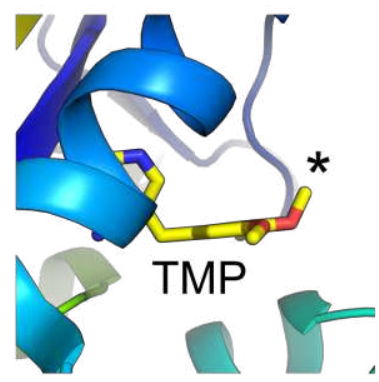

TMP-590 saturation binding in vitro
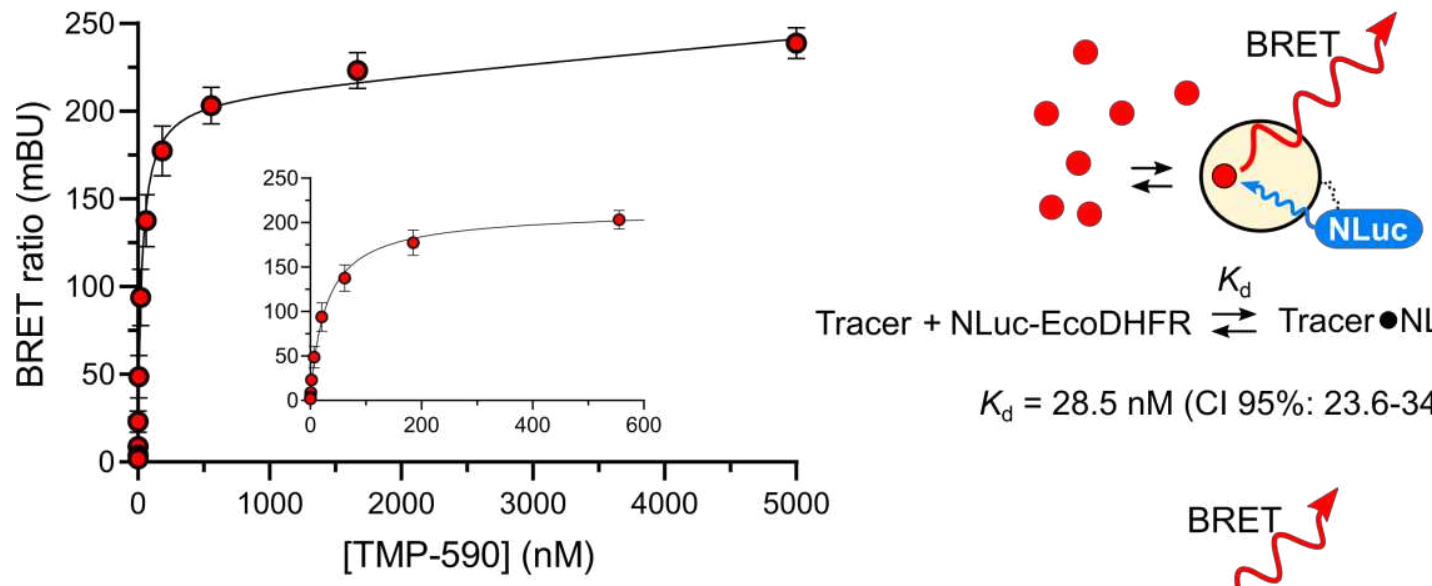

Tracer + NLuc-EcoDHFR $\stackrel{K_{\mathrm{d}}}{\rightleftarrows}$ Tracer $\bullet$ NLuc-EcoDHFR $K_{\mathrm{d}}=28.5 \mathrm{nM}(\mathrm{Cl} 95 \%: 23.6-34.5)$

d

TMP-590 displacement in vitro

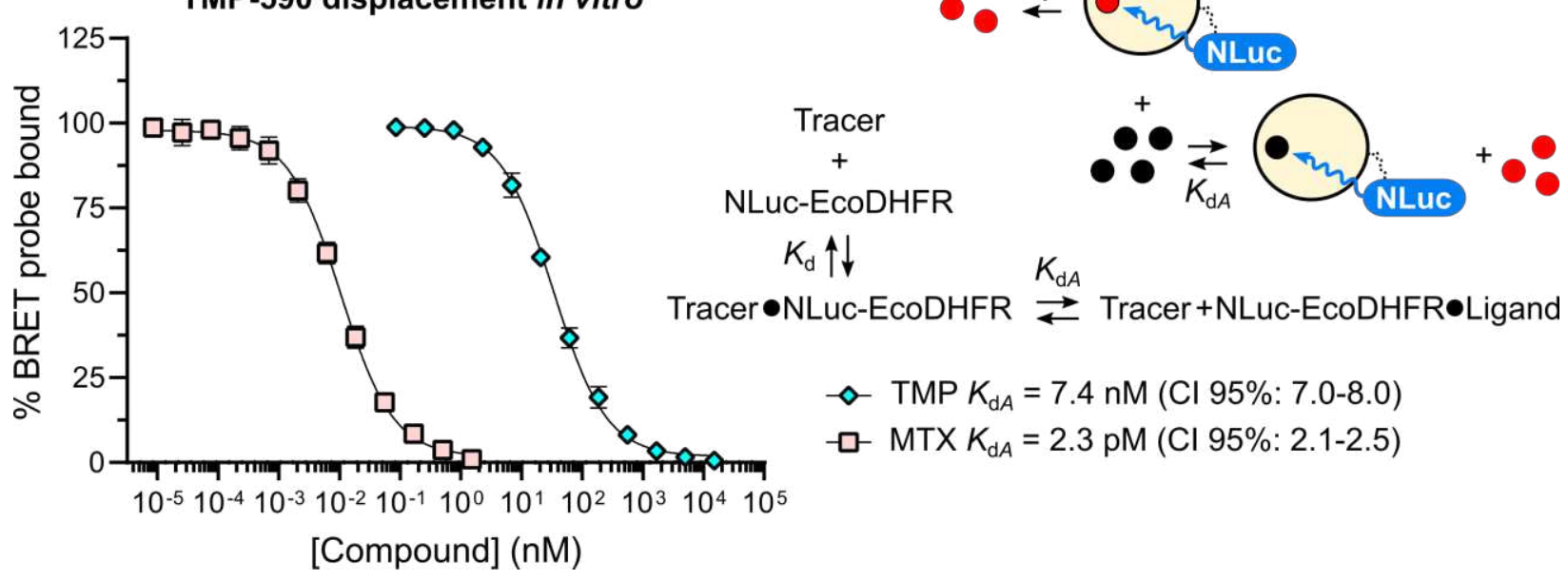

Figure 3 - Design and characterization of BRET acceptor TMP-590 in vitro. a Design strategy for linking the antibiotic (TMP) to a BODIPY-based fluorophore (NanoBRET-590 SE). b Closed-up view of EcoDHFR TMP-binding site (PDB ID: 6XG5). The fluorophore portion of TMP-590 is expected to be exposed to the solvent. Black star indicates the fluorophore attachment point to TMP. c Saturation binding curve of TMP590 to purified NLuc-EcoDHFR in vitro. The indicated dissociation constant $\left(K_{d}\right)$ was obtained by non-linear fitting of experimental data points (red circles - mean \pm SEM of two independent experiments performed in triplicates) to the hyperbolic dose-response equation (solid black line). Inset shows data and fitting at low TMP-590 concentrations. d Competitive displacement of TMP-590 (at $100 \mathrm{nM}$ ) from recombinant 
NLuc-EcoDHFR in vitro by increasing concentrations of MTX (pink squares) or TMP (cyan diamonds). Indicated $K_{\mathrm{dA}}$ values were obtained by non-linear fitting of experimental data points (mean \pm SEM of two independent experiments performed in triplicates) to the competitive binding equation (solid black lines). In $\mathbf{c}$ and $\mathbf{d}$, panels on the right depict the experimental setup and the ligand binding scheme. Red and black circles represent TMP-590 and TMP, respectively.

We next characterized TMP-590 binding properties to NLuc-EcoDHFR in live bacteria. For that, we first performed saturation binding experiments by titrating increasing amounts of the BRET probe onto growth medium containing $E$. coli cells expressing the fusion protein. We observed a dose-dependent increase in BRET signal that reached saturation at high TMP-590 concentrations. Fitting the data as for the in vitro experiments above, and assuming equilibrium conditions, allowed us to calculate an apparent, in-cell, equilibrium dissociation constant ( $\left.K_{\text {d-incell }}\right)$ for TMP-590 of 153.8 nM (Cl 95\%: 127.6-185.6; Fig. 4a), on par with the one obtained in vitro ( $K_{d}=28.5 \mathrm{nM}$; Fig. 3c). These results indicated that TMP-590 permeated $E$. coli cells and interacted with the fusion protein within the bacterial cytoplasm. It is important to note that here we fitted the acquired BRET signal to a simple, bimolecular binding reaction model that makes no mechanistic assumptions about the permeation and clearance rates of TMP-590 (or its competing ligands - see below) through the various E. coli cell compartments (Fig. 4a, right panel). Nevertheless, we anticipate BRET acceptor / donor pairs, like the one developed here, will find use in mechanistic studies aimed at deriving more accurate models of ligand entry and efflux in bacteria, such as the one recently put forward by Westfall and colleagues ${ }^{41}$.

In BRET-based target engagement assays, non-specific binding between BRET donor and acceptor may result in large background signals, increasing data variability and reducing assay quality. Nevertheless, analysis of raw BRET data in the presence of saturating concentrations of TMP showed most of the recorded signal originated from the specific interaction between NLuc-EcoDHFR and TMP-590 in bacteria (Supplementary Fig. 3a). Further, determining the $Z^{\prime}$-factor for BRET assays performed in live bacteria indicated this is a high-quality assay ( $Z^{\prime} \geq 0.5$; Supplementary Fig. $\left.3 b\right)$. The $Z^{\prime}$-factor is a statistical parameter often used to evaluate assay quality and is particularly sensitive to data variability ${ }^{42}$. Together, the above results validated our BRET acceptor / donor design strategy and indicated the assay we developed here is both sensitive and robust, making it a useful tool to evaluate binding of unmodified compounds to the DHFR target in bacteria. 
Figure 4

a

TMP-590 saturation binding in wild-type $E$. coli
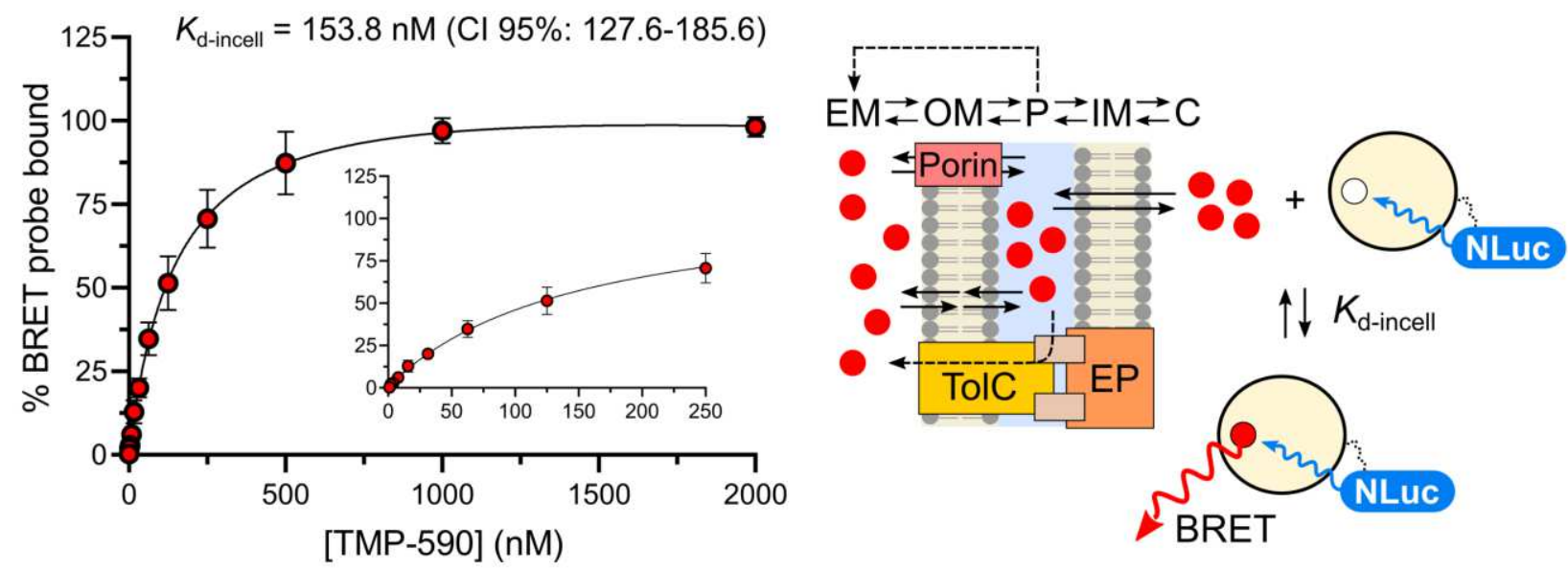

b

TMP-590 equilibrium displacement in wild-type $E$. coli

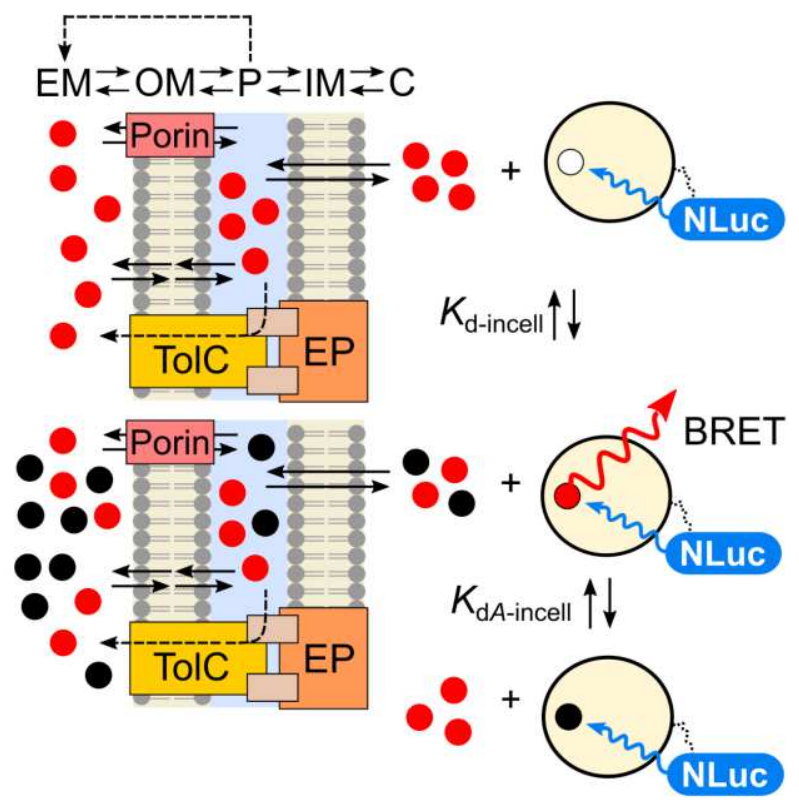

Figure 4 - BRET acceptor TMP-590 is cell permeable and can be competitively displaced by cellpermeable EcoDHFR ligands in E. coli. a Saturation binding curve of TMP-590 to NLuc-EcoDHFR in cultures of wild-type $E$. coli BW25113 ${ }^{43}$. The indicated dissociation constant $\left(K_{\mathrm{d}}\right)$ was obtained by non-linear fitting of experimental data points (mean \pm SEM of three independent experiments performed in triplicates) to the hyperbolic dose-response equation (solid black line). Inset shows data and fitting at low TMP-590 concentrations. b Competitive displacement of TMP-590 (at $400 \mathrm{nM}$ ) from NLuc-EcoDHFR in E. coli cells by increasing concentrations of TMP (diamonds) or MTX (squares). Data points shown are mean \pm SEM of two independent experiments performed in triplicates. Indicated $K_{\mathrm{d} A}$ value was obtained by non-linear fitting of the data to the competitive binding equation (solid black lines). In $\mathbf{a}$ and $\mathbf{b}$, panels on the right depict the experimental setup and the ligand binding scheme. The cellular envelope for a general Gramnegative bacterium is shown. To reach the NLuc-fused target within the bacterial cytoplasm (C), DHFR 
ligands in the extracellular medium (EM) must cross the bacterial cell outer membrane (OM) - most likely via OM porins (depicted); the periplasmic space (P) and the inner membrane (IM). Once in the periplasm, ligands can be removed by the action of bacterial efflux pumps (EP - TolC component is indicated). Red and black circles represent TMP-590 and TMP, respectively.

We expected TMP-590 in-cell equilibrium dissociation constant to amalgamate various probe properties, such as its permeability to $E$. coli and binding potency to the target. To investigate the impact of cell permeability in the observed $K_{\text {d-incell }}$ values, we used a second TMP-based BRET acceptor compatible with NLuc luminescence but not expected to enter bacteria via outer membrane porins due to its large size (TMP-IMP590, Supplementary Fig. 4a). In vitro, TMP-IMP590 potency towards NLuc-EcoDHFR dropped 2.5-fold compared to that of TMP-590 ( $K_{d}$ values of 73.6; 95\% Cl: 69.8-77.5; Supplementary Fig. 4b). Nevertheless, the ability of TMP-IMP590 to interact with NLuc-EcoDHFR in cells was greatly impaired, and we could not accurately determine an apparent binding constant for the bulkier BRET probe $\left(K_{\mathrm{d} \text {-incell }}>3.0\right.$ $\mu \mathrm{M}$; Supplementary Fig. 4c), most likely due to its poor permeability to $E$. coli.

Next, we confirmed $K_{\text {d-incell }}$ values obtained for the BRET probe also reflected TMP-590 binding affinity for its molecular target in cells. For that, we repeated saturation binding experiments using $E$. coli cells expressing a NLuc-fused EcoDHFR having a methionine to valine mutation (at residue 20 in EcoDHFR; M20V) known to make DHFR less sensitive to TMP ${ }^{44,45}$. Indeed, high TMP concentrations (up to $6.7 \mu \mathrm{M}$ ) could not completely quench the mutant EcoDHFR activity in enzymatic assays (Supplementary Fig. 5a). Likewise, in cells, TMP-590 (up to $10 \mu \mathrm{M}$ ) also failed to saturate the mutant fusion protein (Supplementary Fig. 5b). Together, these results indicated that equilibrium dissociation constants obtained using our incell BRET assay reflected both the strength of the interaction between the probe and its molecular target in cells, as well as the ability of the BRET probe to permeate bacteria.

Compound binding potency in bacteria. We next demonstrated BRET TE assays can be used to obtain the equilibrium binding constant of an unlabeled antibiotic to its molecular target within bacteria. The equilibrium binding constant for a ligand to its molecular target is easily obtained in vitro using purified components and routinely employed by medicinal chemists to optimize candidate compounds. Nevertheless, currently there are no methods that can determine equilibrium binding constants of unmodified ligands for their molecular targets within whole bacterial cells. As demonstrated for the BRET probe in the experiments above, we expected the in-cell binding potency of a compound to reflect its ability to permeate bacterial cells and its biochemical binding potency to the target within the bacterial cytoplasm. 
To directly measure the binding affinity of TMP to NLuc-fused EcoDHFR in bacteria, we performed BRET probe displacement experiments in cultures of $E$. coli expressing the fusion protein. Titration of TMP onto medium containing $E$. coli cells expressing NLuc-EcoDHFR and a fixed concentration of TMP-590, resulted in a dose-dependent reduction of the BRET signal, allowing us to estimate an apparent equilibrium dissociation constant for the unmodified antibiotic in $E$. coli $\left(K_{\mathrm{dA} \text {-incell }}\right)$ of $4.9 \mathrm{nM} \mathrm{(95 \%} \mathrm{Cl:} \mathrm{4.2-5.7;} \mathrm{Fig.} \mathrm{4B).}$ This value was in excellent agreement with in vitro binding data obtained using purified NLuc-EcoDHFR $\left(K_{\mathrm{dA}}=7.4 \mathrm{nM}\right.$; Fig. $\left.3 \mathrm{~d}\right)$, indicating that TMP readily permeated the bacteria and that the antibiotic interaction with the fusion protein was not greatly disturbed by components of the bacterial cytoplasm, such as an excess of DHFR substrate. These results showed BRET TE assays can determine the binding strength of an unmodified antibiotic for its molecular target within live bacterial cells in culture, something that has not been shown before.

The action of efflux pumps represents a major obstacle for antibiotic drug discovery ${ }^{4}$. To investigate the impact of efflux pumps in TMP binding to NLuc-fused EcoDHFR in bacteria, we repeated the above experiments using an isogenic TolC-deficient E. coli strain (JW5503-1; Supplementary Fig. 6a) ${ }^{43}$. Bacterial TolC proteins form a channel that traverses the bacterial outer membrane and interacts with bacterial permeases located in the inner membrane to facilitate clearance of a wide range of solutes from the bacterial periplasm ${ }^{46}$. Tolc-dependent efflux pumps include the main E. coli drug efflux pump AcrAB ${ }^{47,48}$. Indeed, TolC-null E. coli were $\sim 3.5$-fold more sensitive to TMP compared to isogenic wild-type cells, suggesting this antibiotic may accumulate to higher concentrations in efflux deficient bacteria (Supplementary Fig. 6b).

To obtain the apparent equilibrium binding constant of TMP for NLuc-DHFR in TolC-null E. coli, we first determined the affinity of its fluorescent derivative, TMP-590, for the fusion protein in these cells. Saturation binding experiments revealed the apparent affinity of the BRET probe for its target increased $\sim 2$-fold in TolC deficient cells compared to the isogenic wild-type cells (strain BW25113) used previously in the experiments above ( $K_{\text {d,in-cell }}=70.9 \mathrm{nM}, \mathrm{Cl} 95 \%$ : 60.6-82.9; Fig. 5a). It is important to note that the ratiometric nature of BRET assays mitigates potential assay differences, such as variations in cell numbers or in fusion protein expression levels, and allows direct comparison of binding constants obtained using different bacterial strains ${ }^{20}$. Indeed, in the absence of TMP-590, raw BRET signals were very similar in both wild-type and TolC-null cells, indicating both strains had similar background BRET levels due to NLucEcoDHFR-generated luminescence. On the other hand, in the presence of TMP-590, raw BRET levels were significantly higher in TolC-null cells compared to wild-type cells (Supplementary Fig. 3b). Together, these 
results suggested the TMP-based BRET probe accumulated to higher concentrations in efflux pumpdeficient E. coli. A similar observation was reported by Cooper and colleagues for a different fluorescent TMP derivative ${ }^{49}$.

Despite differences in TMP-590 accumulation, the apparent equilibrium binding constant values of unmodified TMP were nearly identical in both wild-type $\left(K_{\mathrm{dA} \text {-incell }}=4.9 \mathrm{nM}, \mathrm{Cl} 95 \%\right.$ : 4.2-5.7; Fig. $\left.4 \mathrm{~b}\right)$ and TolC-null cells $\left(K_{\mathrm{dA} \text {-incell }}=4.7 \mathrm{nM}, \mathrm{Cl} 95 \%\right.$ : 4.1-5.4; Fig. $\left.5 \mathrm{~b}\right)$. These findings suggested that under the experimental conditions used here, the action of efflux pumps did not impact the intracellular concentration of the unmodified antibiotic. The disconnect between the observed higher sensitivity of TolC-null E. coli to TMP (Supplementary Fig. 6b) and our data from competitive binding assays performed under equilibrium conditions was likely due to differences in compound incubation times used in these experiments (a few minutes for the binding assays versus several hours for MIC determination).

To show BRET TE assays can illuminate antimicrobial resistance mechanisms, we investigated the ability of MTX to displace TMP-590 from NLuc-EcoDHFR in isogenic E. coli cells with and without efflux pumps. MTX is a potent DHFR ligand and folate-competitive inhibitor in vitro (Fig 3b, Supplementary Fig. 2b), but has no antimicrobial activity in wild-type E. coli (MIC > $100 \mu \mathrm{M}$; Supplementary Fig. 6b). Efflux pumps are thought to play a role in MTX lack of biological activity because, at high concentrations, this compound inhibits the growth of TolC-null E. coli (MIC $=28.0 \mu \mathrm{M}, \mathrm{Cl} 95 \%$ : 27.5-35.3; Supplementary Fig. 6b) ${ }^{46,50-52}$. Nevertheless, MTX failed to displace TMP-590 from the fusion protein in both wild-type and TolC-null $E$. coli, indicating the compound did not accumulate at high enough concentrations within these cells during the course of the experiment (Figs. $4 \mathrm{~b}$ and $5 b$ ). These results suggested MTX is poorly permeable to $E$. coli and demonstrated BRET TE assays can be used to rapidly obtain information on antimicrobial resistance mechanisms. 
Figure 5

a

TMP-590 saturation binding in E. coli without efflux pumps
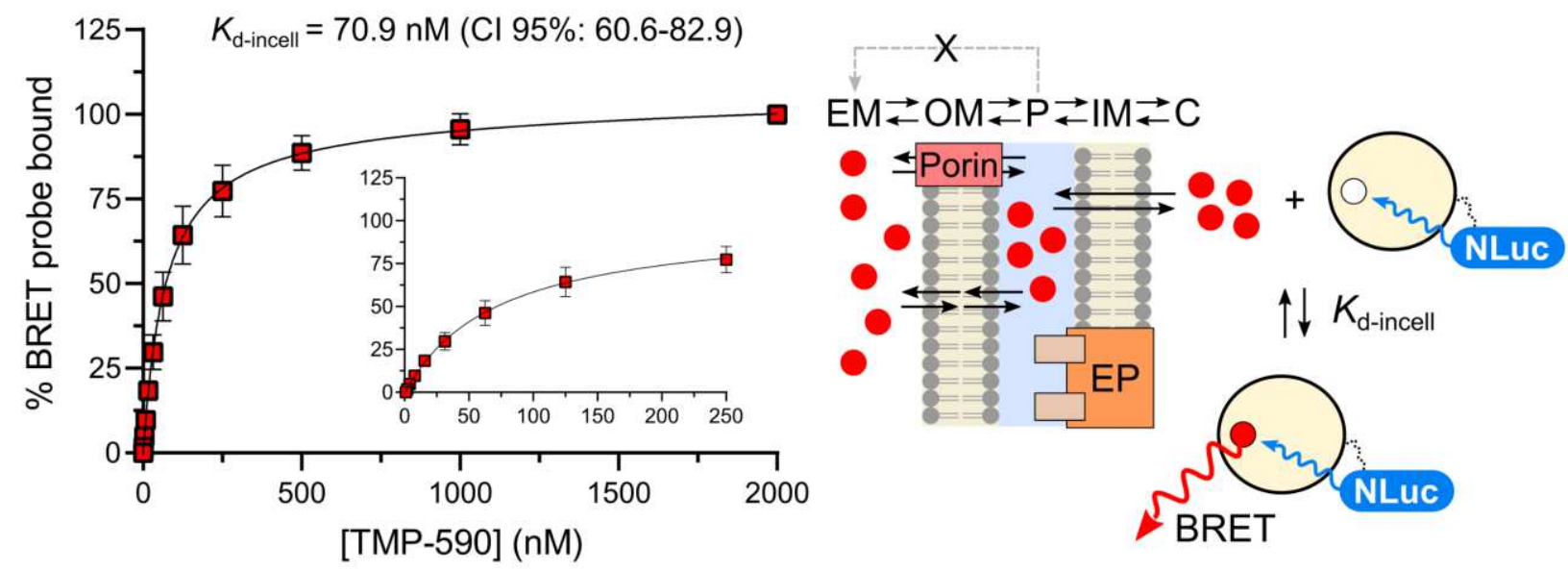

b

TMP-590 equilibrium displacement in E. coli without efflux pumps
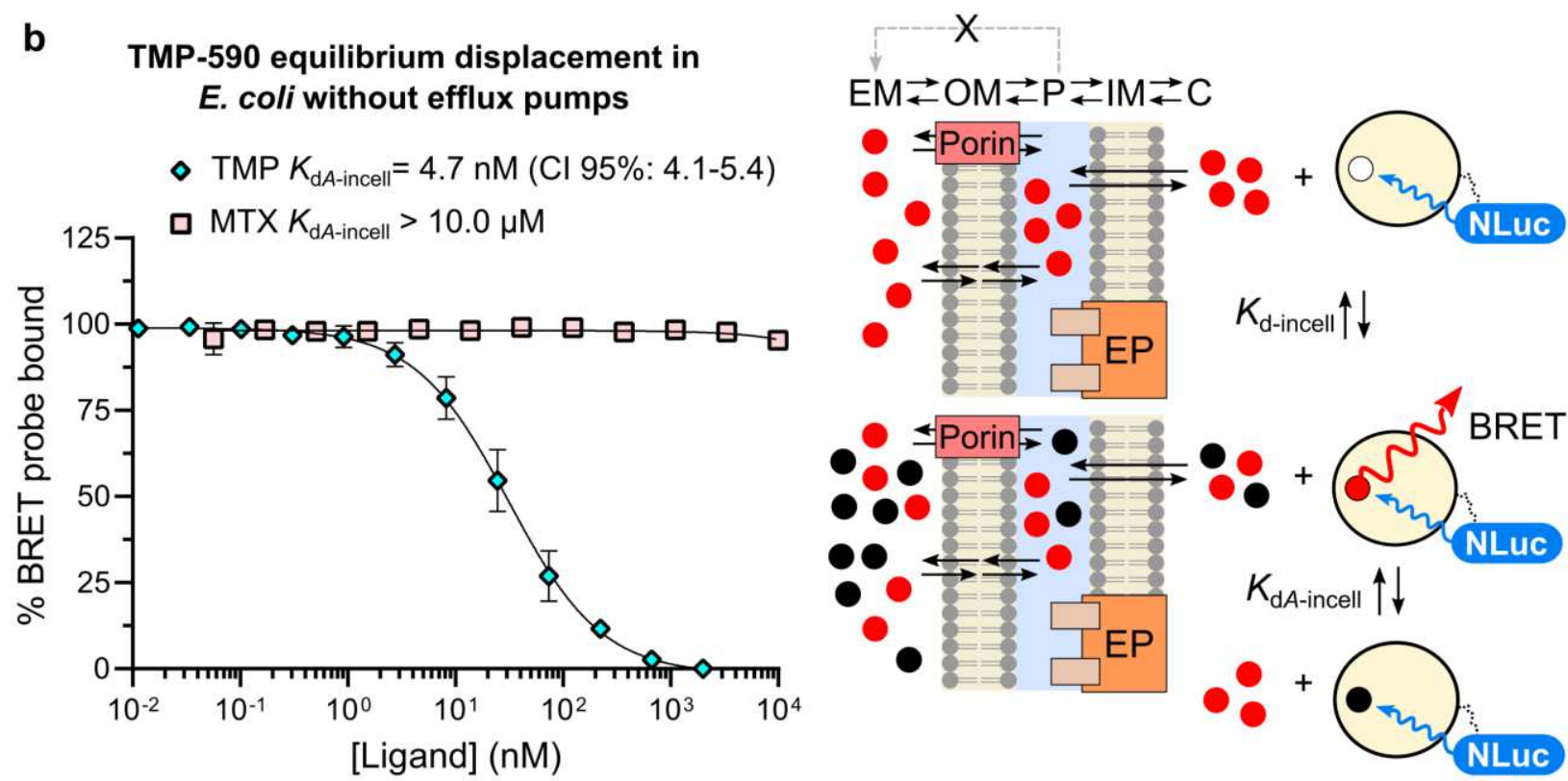

Figure 5 - Deletion of tolC has only a small impact on TMP-590 displacement by cell-permeable EcoDHFR ligands in E. coli. a TMP-590 saturation binding in cultures of TolC-null (JW5503-1, $\Delta$ tolC) cells expressing NLuc-EcoDHFR. The indicated dissociation constant $\left(K_{d}\right)$ was obtained by non-linear fitting of experimental data points (mean \pm SEM of three independent experiments performed in triplicates) to the hyperbolic dose-response equation ( solid black line). Inset shows data and fitting at low TMP-590 concentrations. $\mathbf{b}$ Competitive displacement of TMP-590 (at $400 \mathrm{nM}$ ) from NLuc-EcoDHFR in $\Delta$ tolC (JW5503-1) cells by increasing concentrations of TMP (diamonds) or MTX (squares). The indicated $K_{\mathrm{d} A}$ value was obtained by non-linear fitting of experimental data points (mean \pm SEM of two independent experiments performed in duplicates) to the competitive binding equation (solid black lines). In $\mathbf{a}$ and $\mathbf{b}$, panels on the right depict the experimental setup and the ligand binding scheme. The cellular envelope for a general Gram-negative bacterium is shown. To reach the NLuc-fused target within the bacterial cytoplasm (C), DHFR ligands in the extracellular medium (EM) must cross the bacterial cell outer membrane (OM), periplasmatic space 
(P) and inner membrane (IM). The $X$ in the binding scheme indicates TolC-dependent efflux pumps (EP) are not active in TolC-null cells. Red and black circles represent TMP-590 and TMP, respectively.

Together, our results demonstrated BRET TE assays performed under equilibrium conditions can provide quantitative binding data that reflects both cell permeability and biochemical potency of antibiotics for their molecular targets within E. coli. Satisfyingly, these results were in line with the observed biological activities of TMP and MTX in E. coli. Despite being a considerably more potent DHFR inhibitor and binder than TMP in vitro, MTX failed to displace TMP-590 in E. coli cells. These results suggested MTX was poorly permeable to $E$. coli, providing further insights into the bacteria resistance mechanism to this compound. Further, our results also demonstrated that the same matched pair of BRET donor and acceptor can be readily transferred to different $E$. coli strains to investigate the impact of individual bacterial components on target engagement.

Compound residence time in bacteria. Our results above showed TMP equilibrium binding constant in $E$. coli was unaffected by the action of efflux pumps, despite the increased sensitivity of TolC-null E. coli to this antibiotic. These observations suggested determining $K_{\mathrm{d} A \text {-incell }}$ values using BRET-based target engagement assays, although useful to identify cell-permeable compounds and to drive compound optimization campaigns, may not be sufficient to predict the effectiveness of a compound against the bacteria. Antibiotic clearance by efflux pumps can lead to antimicrobial resistance by reducing the effective intracellular concentration of the drug over time ${ }^{4,19,53,54}$. Accordingly, compounds having longer on-target residence times ( $\tau$, defined as the reciprocal of the dissociation rate constant $k_{\text {off }}$ ) within bacteria are expected to have reduced clearance and, consequently, improved biological properties ${ }^{53,54}$. Nevertheless, currently there are no methods that can estimate $k_{\text {off }}$ values for unmodified antibiotics and their molecular targets in live bacteria.

In vitro, dissociation rate constants for unlabeled ligands are determined using the methods originally developed by Motulsky and Mahan 55,56. A prerogative of these methods, and their variations, is that the concentration of the fluorescent probe must remain constant throughout the experiment. In vitro, this condition is easily met. However, in cells, the action of efflux pumps could prevent these analyses. To ascertain if bacterial efflux pumps cleared the BRET probe from cells, we performed time course experiments to monitor the interaction between TMP-590 and NLuc-EcoDHFR in wild-type E. colicells (Fig. $6 \mathrm{~A})$. Our results revealed the BRET probe rapidly entered the bacteria, reaching maximum receptor occupancy within the first 20 minutes of the experiment. Nevertheless, after this initial period, the BRET 
signal gradually decreased before reaching a plateau. These changes in BRET response over time were not due to fluctuations in the levels of NLuc-fused target protein, as the raw BRET signal remained constant throughout the duration of the experiment for the no tracer control (Supplementary Figure 7). Together, these observations suggested the fall in BRET signal over time was likely due to TMP-590 being cleared out of wild-type $E$. coli by the action of efflux pumps, as seen before for a different fluorescent TMP derivative ${ }^{49}$. The observation that TMP-590 concentration changed over time in wild-type E. coli prevented us from estimating dissociation rate constants, and, consequently, residence times, for unlabeled DHFR ligands in these bacteria. Currently, we are working on the development of novel BRET probes resistant to the action of bacterial efflux pumps, as those would enable us to assess the impact of individual bacterial components on the retention of antibiotics in efflux-competent bacteria.

To further verify the action of $E$. coli efflux pumps was indeed behind TMP-590 clearance from wild-type cells, we repeated the time-course experiment using TolC-null cells (Fig. 6B). As observed for the wildtype bacteria, the BRET probe rapidly entered efflux-deficient bacteria, saturating the NLuc-fused target within the first $\sim 20$ minutes of the experiment. Nevertheless, differently from what was seen in wild-type cells, in efflux-deficient bacteria, the BRET signal did not fall over time. These results suggested TMP-590 was indeed cleared from wild-type cells via the action of efflux pumps. Interestingly, TMP-590 association rate constant $\left(k_{\text {obs-incell }}\right)$ was identical in bacteria with and without efflux pumps $\left(0.3 \mathrm{~min}^{-1}, \mathrm{Cl} 95 \%\right.$ : 0.2-0.4, Fig. 6A,B), suggesting the action of efflux pumps had little to no impact on the early stages of TMP-590 target engagement in bacteria.

The observation that TMP-590 concentration did not change over time in efflux-deficient $E$. coli encouraged us to use a variation of the Motulsky and Mahan method to estimate residence time of unlabeled TMP in these bacteria. For that, TolC-null E. coli were first pre-incubated with varying concentrations of TMP. Then, the antibiotic was washed out and binding of TMP-590 to NLuc-EcoDHFR was monitored in real time (Fig 6B). The resulting data was fitted to a variant of the original Motulsky and Mahan competitive binding equation derived by Hoare and colleagues ${ }^{56,57}$ to estimate the in-cell dissociation rate constant ( $k_{\text {off-incell }}$ ) for unlabeled TMP. Previous work using purified EcoDHFR showed TMP had a residence time of $8.0 \mathrm{~min}^{58}$. By contrast, TMP had a much longer (9-fold) on-target residence time in E. coli lacking efflux pumps ( $\tau_{\text {incell }} 73.9$ min; Fig. 6b). The development of novel efflux-resistant BRET tracers for DHFR ligands will allow us to further investigate the effect of bacterial efflux pumps in TMP clearance from wild-type E. coli. Nevertheless, results obtained using TolC-null cells were in line with our 
data from phenotypic assays that showed $E$. coli without efflux pumps are $\sim 3.5$-fold more sensitive to TMP than the wild-type (Supplementary Fig. 5b), and from previous antibiotics accumulation experiments using LC-MS/MS ${ }^{51}$. Together, results from time-course experiments demonstrated BRET TE assays can provide kinetic binding parameters of antibiotics for their molecular targets in bacteria, something that has not been shown before. 
Figure 6

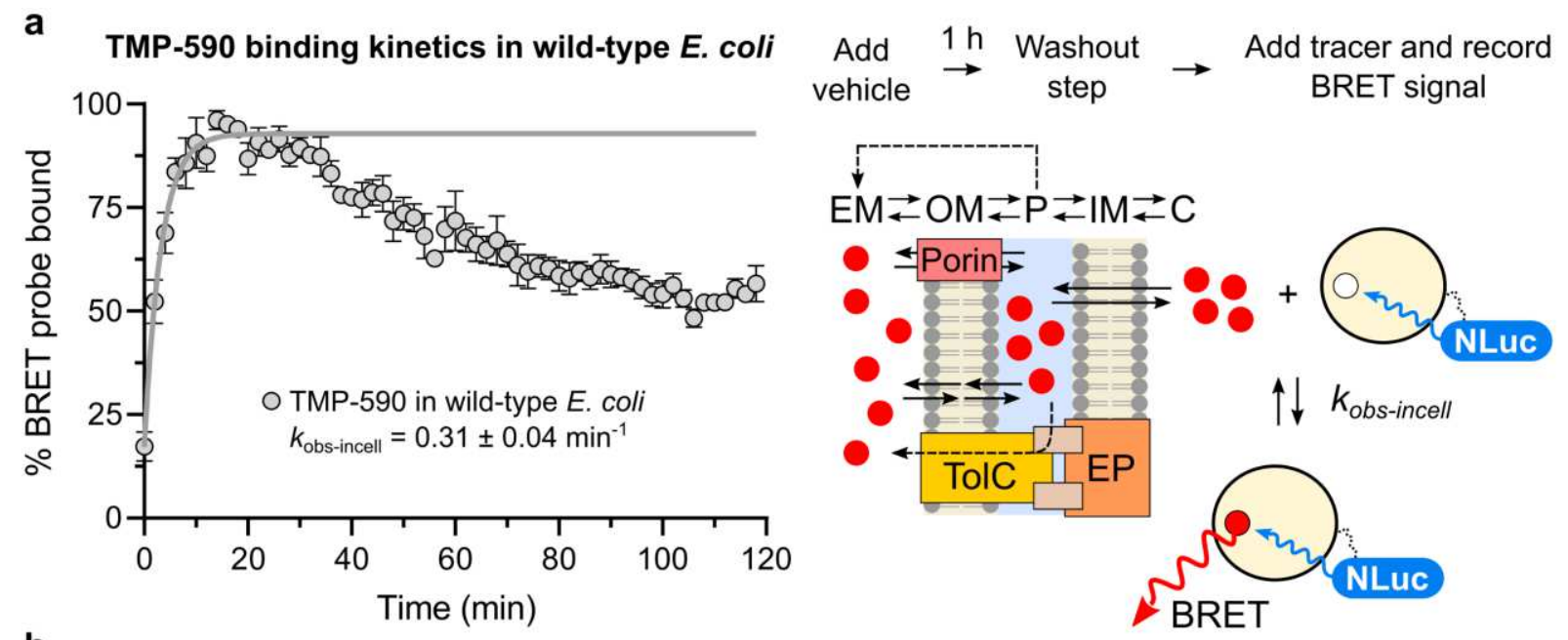

b

TMP-590 binding kinetics in E. coli without efflux pumps
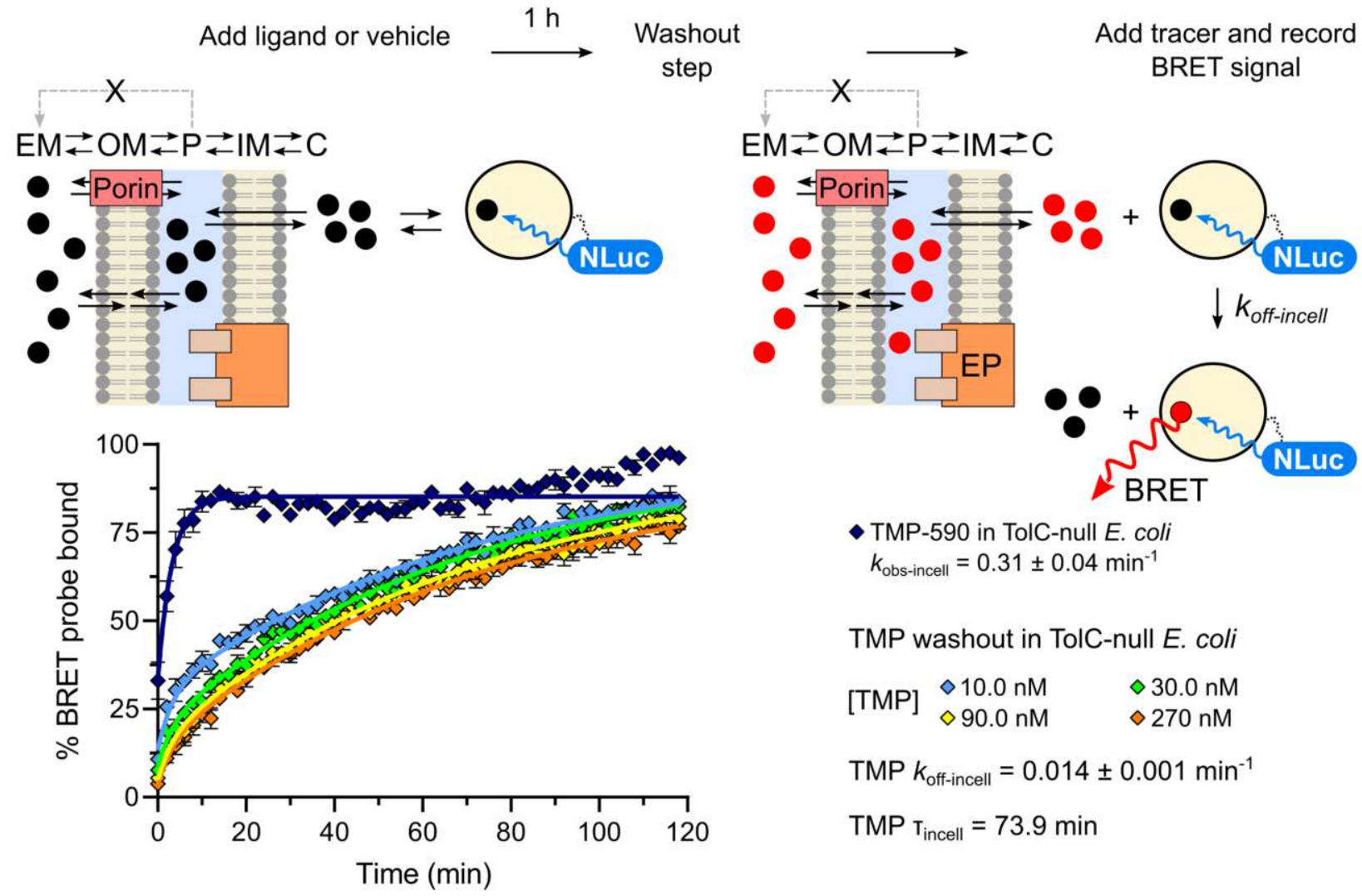

Figure 6 - Real time TMP-590 target engagement in wild-type and TolC-null E. coli and TMP residence time in TolC-null cells. Time-course profiles of TMP-590 binding to NLuc-EcoDHFR in isogenic wild-type (a; gray circles) and TolC-null E. coli (b; blue diamonds). For these experiments, cells were incubated for 1 $\mathrm{h}$ with vehicle (DMSO) or, in b, with varying TMP concentrations (indicated by different colors), collected by centrifugation and suspended in fresh medium containing saturating concentrations of TMP-590 (1.0 $\mu \mathrm{M})$. BRET signal was followed for $2 \mathrm{~h}$ after adding the probe to the medium. Indicated $k_{\text {obs-incell }}$ values 
were obtained by non-linear fitting of experimental data points (mean \pm SEM of two independent experiments performed in duplicate; limited to the initial $20 \mathrm{~min}$ ) to the one-phase association equation (solid lines). Fitting of the data was extended to the whole time course to highlight the effect of efflux pumps in the BRET response. In b, the $k_{\text {off-incell }}$ value indicated was obtained by fitting the data (mean \pm SEM of two independent experiments performed in duplicate) to a variant of the competitive binding equation (see Methods). $\tau_{\text {incell }}$ value is the reciprocal of $k_{\text {off-incell }}$ Images on the right of panel (a) and top of panel (b) depict the experimental setup and the ligand binding scheme. The cellular envelope for a general Gram-negative bacterium is shown. To reach the NLuc-fused target within the bacterial cytoplasm (C), DHFR ligands in the extracellular medium (EM) must cross the bacterial cell outer membrane (OM), periplasmatic space $(P)$, and inner membrane (IM). The $X$ in the binding scheme in panel (b) indicates that TolC-dependent efflux pumps (EPs) are not active in TolC-null cells. Red and black circles represent TMP590 and TMP, respectively.

Time-course profiles of TMP-590 and NLuc-EcoDHFR in isogenic wild-type (gray circles) and TolC-null $E$. coli (blue diamonds). Indicated $k_{\text {obs-incell }}$ values were obtained by non-linear fitting of experimental data points (limited to the initial 20 minutes) to the one-phase association equation (solid lines). Fitting of the data was extended to the whole time course to highlight the effect of efflux pumps in the BRET response. For the antibiotic washout experiment, cells were incubated for one hour with varying TMP concentrations (indicated by different colors), collected by centrifugation and suspended in fresh medium containing saturating concentrations of TMP-590 $(1.0 \mu \mathrm{M})$. BRET signal was followed for 2 hours after adding the probe to the media. $k_{\text {off-incell }}$ value indicated was obtained by fitting the data to a variant of the competitive binding equation (see Methods). $\tau$ incell value is the reciprocal of $k_{\text {off-incell. }}$ In $\mathbf{a}$ and $\mathbf{b}$, panels on the right (a) and top (b) depict the experimental setup and the ligand binding scheme. The cellular envelope for a general Gram-negative bacterium is shown. To reach the NLuc-fused target within the bacterial cytoplasm (C), DHFR ligands in the extracellular medium (EM) must cross the bacterial cell outer membrane (OM), periplasmatic space (P) and inner membrane (IM). The $\mathbf{X}$ in the binding scheme in $\mathbf{b}$ indicates TolC-dependent efflux pumps (EP) are not active in TolC-null cells. Red and black circles represent TMP-590 and TMP, respectively.

Identifying a compound mechanism of action. Historically, antimicrobials discovery has relied heavily on target-agnostic, phenotypic screens ${ }^{59}$. Thus, in addition to showing BRET TE in bacteria can provide medicinal chemists with familiar equilibrium and kinetics parameters to build SAR and guide compound progression, we also sought to demonstrate these assays can rapidly establish the mechanism of action of potential antibiotics identified in whole cell phenotypic screens. Establishing the mechanism of action of early hit compounds can de-risk their progression by increasing the confidence that compound improvement in biological activity is due to on-target effects ${ }^{60}$. Nevertheless, current target deconvolution methods are labor and resource intensive requiring the generation of resistant mutants or the use of chemoproteomics strategies, for example ${ }^{10}$. 
To identify novel, cell-permeable, DHFR inhibitors with biological activity in wild-type $E$. coli, we first screened a focused compound library based on P218, a Plasmodium falciparum DHFR inhibitor currently undergoing clinical trials for malaria (ClinicalTrials.gov Identifier: NCT03707041) ${ }^{61}$. Out of the 175 compounds in this library, we identified one (1244) that inhibited wild-type E. coli growth by more than $50 \%$ at $10 \mu \mathrm{M}$ and had single-digit $\mu \mathrm{M}$ activity against the bacteria in a dose-response experiment (Fig. 7a-c; MIC $=8.3 \mu \mathrm{M}, \mathrm{Cl}$ 95\%: 6.7-13.1). P218 had no antimicrobial activity against $E$. coli. Compound 1244 has a quinazoline moiety and a $\mathrm{Cl}$-phenyl group joined via a sulfur atom, and its structure combines pharmacophores present in known antifolate antibiotics, such as trimetrexate, which contains a quinazoline moiety, and pyrimethamine, which contains a Cl-phenyl group ${ }^{62}$. Next, we used our DHFR BRET TE assay to show 1244 efficiently displaced TMP-590 from NLuc-fused EcoDHFR in E. coli cells ( $K_{\mathrm{d} A-}$ incell $=1.9 \mathrm{nM}, \mathrm{Cl}$ 95\%: 1.6-2.2; Fig. 7d), suggesting DHFR inhibition as the likely mechanism of action for this compound. Together, these results demonstrated the utility of BRET-based target engagement assays in bacteria to rapidly propose potential mechanisms of action for hit compounds identified in phenotypic screens.

\section{Figure 7}

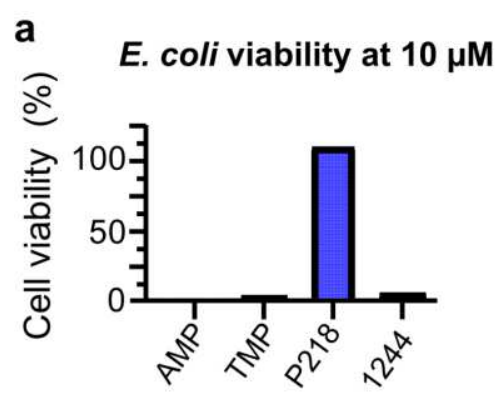

C

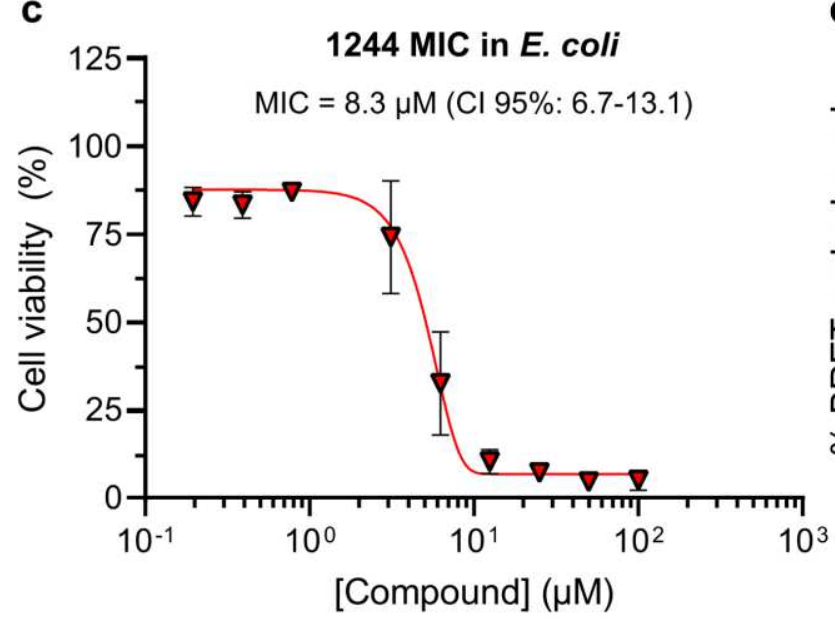

b P218 and 1244 chemical structures
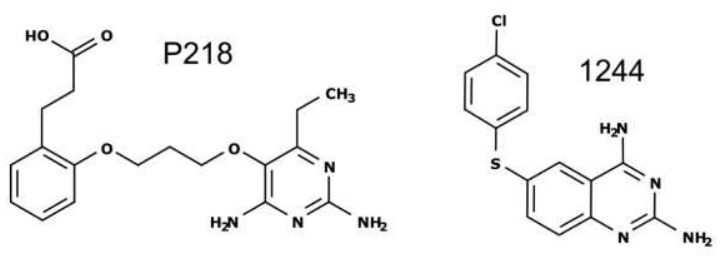

d

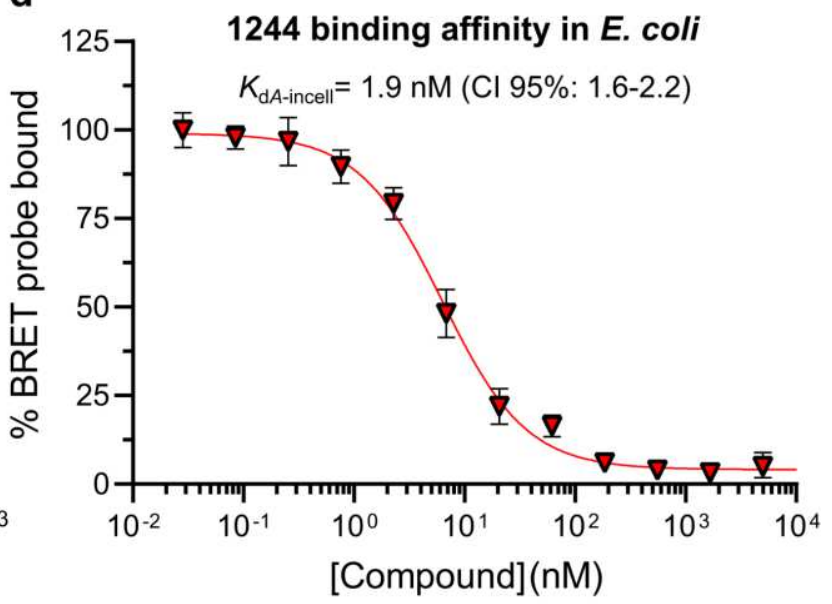


Figure 7 - Identification of DHFR inhibition as potential MOA for compound 1244 identified in a E. coli phenotypic screen. a $E$. coli viability at a single concentration $(10 \mu \mathrm{M})$ for TMP, P218 and 1244. Ampicillin (AMP, $10.0 \mathrm{mg}^{\mathrm{mL}} \mathrm{L}^{-1}$ ) and TMP were used as positive controls. Data shown are $\%$ cell viability compared to no compound control (single measurements from a single experiment). b Chemical structures for P218 and 1244. c Determination of minimum inhibitory concentration (MIC) for 1244 . MIC values indicated in parenthesis were calculated by extrapolating a tangent from the inflexion point of a fitted Gompertz curve (solid line) to the no-growth line ${ }^{36}$. Data shown are mean \pm SEM of two independent experiments performed in duplicates. $\mathbf{d}$ Competitive displacement of TMP-590 (at $85 \mathrm{nM}$ ) from NLuc-EcoDHFR in E. coli $\mathrm{BL21(De3)}$ by increasing concentrations of 1244 . $K_{\mathrm{d} A}$ values were obtained by non-linear fitting of experimental data points (mean \pm SEM of at two independent experiments performed in triplicates) to the competitive binding equation (solid line).

Transfer of DHFR BRET TE assay to Mycobacteria. To counter AMR in the various human bacterial pathogens, the speed at which new antibiotics are discovered and progressed needs to increase manyfold ${ }^{6-8}$. One of the obstacles to the discovery of novel antibiotics is that compound permeability and clearance rules for different bacteria are poorly understood and are likely to vary widely amongst human bacterial pathogens due to differences in bacterial envelope composition, including the identities and expression levels of outer membrane porins and efflux pumps. For example, porins in the outer membrane of $E$. coli discriminate solvent molecules based on their size, shape and electrostatic properties, whereas Pseudomonas aeruginosa has a large collection of substrate-specific porins ${ }^{12,19,63}$. A proven strategy to accelerate efforts in drug discovery is to develop tools and reagents that can be readily used across different biological systems ${ }^{64}$. Accordingly, TMP-590 design strategy intended to make it a useful tool to investigate target engagement by DHFR ligands across multiple bacteria. TMP is known to bind to a wide range of microbial DHFR enzymes ${ }^{65}$, and its fluorescent derivative, TMP-590, conforms to known requirements for compounds to enter bacterial cells via $E$ coli-like general porins, which are present in all major groups of bacterial pathogens, including Gram-positives, Gram-negatives and Mycobacteria ${ }^{39,66,67}$.

To demonstrate TMP-590 can be used in bacteria other than E. coli, we employed this BRET probe to investigate target engagement in Mycobacterium abscessus. M. abscessus is a multi-drug resistant, emerging human pathogen that causes severe respiratory, skin and mucosal infections ${ }^{30,68}$. Antibiotic resistance in $M$. abscessus is attributed to a combination of factors, including the presence of a mycolic acid-rich cell wall and a large number of drug efflux pumps and inactivating enzymes ${ }^{5,69}$. We showed TMP590 permeated this mycobacterium by titrating increasing concentrations of the BRET probe onto cultures of $M$. abscessus expressing NLuc-fused M. abscessus (Mab)DHFR. These saturation binding curves allowed us to estimate an apparent in-cell binding affinity of 52 nM for TMP-590 to NLuc-fused MabDHFR (Fig. 8a). 
Conversely, addition of increasing amounts of TMP to the culture medium displaced the BRET probe from the NLuc-fused target protein in a dose-dependent manner, resulting in an apparent in-cell inhibitor binding constant of $2.2 \mathrm{nM}$ for the unmodified antibiotic (Fig. 8b). Results in M. abscessus were in excellent agreement with our previous observations using $E$. coli, and indicated TMP-590 may indeed be used across multiple bacteria to aid in the discovery and optimization of novel ligands to bacterial DHFR. 


\section{Figure 8}

a TMP-590 saturation binding in $M$. abscessus

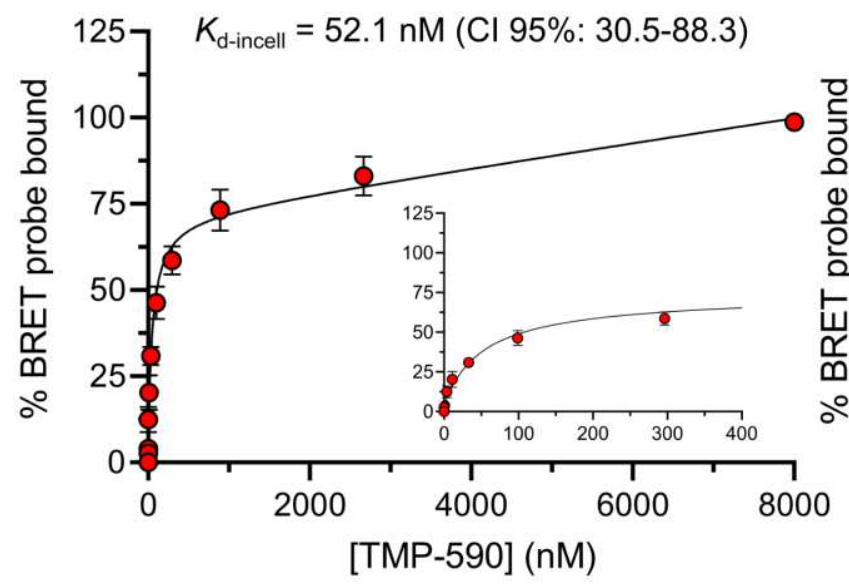

b TMP binding affinity in $M$. abscessus

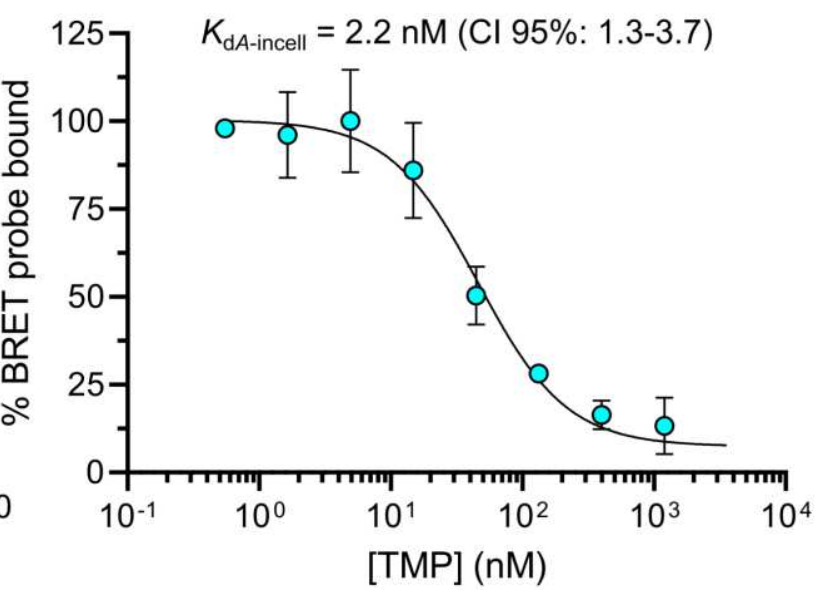

Figure 8 - DHFR BRET-based target engagement can be readily transferred to Mycobacterium abscessus. a Saturation binding curve of TMP-590 in M. abscessus cells expressing NLuc-MabDHFR. The indicated dissociation constant $\left(K_{\mathrm{d}}\right)$ was obtained by non-linear fitting of experimental data points (mean \pm SEM of two independent experiments performed in duplicates) to the hyperbolic dose-response equation (black line). Inset shows data and fitting at low TMP-590 concentrations. b Competitive displacement of TMP590 (at $1.00 \mu \mathrm{M}$ ) from NLuc-MabDHFR in M. abscessus cells by increasing concentrations of TMP. The indicated $K_{\mathrm{d} A}$ values were obtained by non-linear fitting of experimental data points (mean $\pm \mathrm{SEM}$ from a single experiment performed in duplicates) to a competitive (one-site) model (solid black lines). The ligand binding scheme in M. abscessus is expected to be similar to the one shown in Fig. 4 for E. coli.

\section{Conclusion}

We described here the development of a novel target engagement assay to obtain equilibrium and kinetic binding parameters of unmodified antibiotics to the antimicrobial drug target DHFR in whole bacterial cells. We also demonstrated custom-made pairs of matched BRET donor and acceptor can be easily transferred to different bacteria, enabling mechanistic studies to identify cellular components important for antibiotics permeation and clearance. Determining equilibrium and kinetic binding parameters of antibiotics to their molecular targets within live bacteria using BRET TE assays should enable the systematic investigation of the physicochemical properties needed for compounds to gain access to bacteria and evade efflux pumps, thus providing a valuable tool for researchers to overcome the two major hurdles in target-based antimicrobial discovery programs: the poor compound permeability of the bacterial envelope and compound clearance by the action of bacterial efflux pumps. This method can also be used to rapidly identify the potential mechanism of action of hit compounds, which is a major hurdle 
in antibiotic discovery programs based on whole-cell phenotypic screens. Further, the high quality of the BRET-based assay reported here $\left(Z^{\prime} \geq 0.5\right)$ should also enable its use in high-throughput screening campaigns to identify novel, cell-permeable DHFR ligands. Nevertheless, for these activities, one should be mindful of potential false positive compounds causing BRET response attenuation due to quenching of donor and acceptor signals. In most cases, these nuisance compounds may be detected by analyzing donor and acceptor signals individually ${ }^{70}$. Nevertheless, orthogonal assays, such as the DHFR enzymatic assay used here, should be employed to confirm the activity of hit compounds.

We expect the development of similar BRET-based target engagement assays in bacteria to help accelerate the discovery of novel antimicrobials and advance our understanding of AMR mechanisms in a wide range of bacteria. This method should be generally applicable to other antimicrobial targets that, such as DHFR, have synthetically-tractable, biologically-active ligands. Although not essential, having structural information for the target protein (or a closely-related homologue) and knowing the ligand binding mode within the target should simplify BRET tracer design. Here, we showed our TMP-based BRET tracer interacted with the DHFR enzymes from two different organisms. Conversely, one could explore the use of a promiscuous binder as a scaffold for a novel BRET tracer capable of interacting with different targets. For example, BRET tracers based on promiscuous kinase inhibitors could enable this assay for the multiple serine-threonine kinases found in M. tuberculosis ${ }^{71}$. One promising application for this assay that we did not explore here is to find tractable, cell-permeable chemical matter for drug targets recalcitrant to recombinant production or that are part of large protein complexes whose functions are hard to reconstitute using in vitro strategies, such as the Clp Protease ${ }^{72,73}$.

\section{Methods}

\section{Bacterial strains and plasmid DNAs used for cloning and BRET TE assays in bacteria}

All DNA cloning was performed in E. coli Mach1 (ThermoFisher Scientific, catalogue\# C862003). BRET TE for compound 1244 was performed in E. coli BL21De3-R ${ }^{35}$, a kind gift of Professor Opher Gileadi (SGCOxford, United Kingdom). All other BRET TE assays reported here used wild-type E. coli BW25113 cells or its isogenic TolC-null mutant (JW5503-1), both from the Keio collection ${ }^{43}$ and a kind gift of Professor Beny Spira (University of São Paulo, Brazil). For BRET TE assays in BL21De3-R, the BRET donor was expressed from a pET28-derivative plasmid (pNIC28-Bsa4) ${ }^{35}$, whereas for BRET TE assays in the Keio collection strains the BRET donor was expressed from plasmid pBAD24 ${ }^{74}$. For BRET TE in M. abscessus, the BRET donor was 
integrated into the bacterial genome using the integrative vector pMV306hsp ${ }^{75}$. See below for further details on cloning strategies.

\section{Cloning of wild-type Eco-DHFR and NLuc-fused EcoDHFR and MabDHFR}

Oligonucleotide primers, genomic (g)DNA, plasmid DNA used in this work can be found in Supplementary Table S1. We used a two-step cloning strategy to generate the in-frame fusion of NLuc (N-terminal portion) to EcoDHFR or MabDHFR (C-terminal portion). NLuc coding sequence was amplified via PCR using Promega's NanoLuc-AAK1 Fusion vector (catalogue\# NV1001) as template and primers NLuc-F1 and NLucR1. This template/primer combination maintained a stretch of 9 additional amino acids at the C-terminal of NLuc (Gly-Ser-Ser-Gly-Ala-Ile-Ala-Gly-Ser) found in the original Promega plasmid. The amplicon was introduced via ligation independent cloning (LIC) into pNIC28-Bsa4, a pET28-based plasmid that confers kanamycin resistance $\left(\operatorname{Kan}^{R}\right)^{35}$. This cloning strategy introduced an $\mathrm{N}$-terminal six-histidine tag followed by the tobacco etch virus (TEV) protease recognition site to NLuc. EcoDHFR was PCR-amplified from E. coli Mach1 genomic DNA using primers EcoDHFR-F1 and EcoDHFR-R1. The resulting amplicon was introduced into pNIC28-Bsa4 containing NLuc using BamHI and Hindlll restriction sites present in both amplicon and plasmid. The NLuc-EcoDHFR insert was transferred via restriction enzyme cloning to pBAD24 ${ }^{74}$. Wild-type M. abscessus (Mab)DHFR (ATCC 19977 strain) was amplified from plasmid DNA (MyabA.01062.a.B15.GE43312, a kind gift from the Seattle Structural Genomics Center for Infectious Disease) using primers MabDHFR-F1 and MabDHFR-R1 and introduced into pNIC28-Bsa4 containing NLuc as described above for EcoDHFR. The NLuc-MabDHFR insert was then transferred via restriction enzyme cloning to the mycobacterial integrative vector pMV306hsp ${ }^{75}$. The resulting construct in pMV306hsp was introduced into M. abscessus cells via electroporation. Wild-type EcoDHFR was cloned into pET28-Bsa4 from genomic DNA via a similar LIC-based strategy but used primers EcoDHFR-F2 and EcoDHFR-R2. As above, this cloning strategy introduced a TEV protease-cleavable, $\mathrm{N}$-terminal six-histidine tag to EcoDHFR. All clones were verified by DNA sequencing.

\section{Recombinant production of wild-type and NLuc-fused EcoDHFR}

Plasmids of interest were introduced into chemically-competent E. coli BL21(DE3)-pRARE2-R3 ${ }^{35}$, via the heat shock method. Transformants were selected on LB-agar (for $\sim 16 \mathrm{~h}$ at $37^{\circ} \mathrm{C}$ ) complemented with 50 $\mu \mathrm{g} / \mathrm{mL}$ kanamycin and $35 \mu \mathrm{g} / \mathrm{mL}$ chloramphenicol. Single colonies were used to inoculate $50 \mathrm{~mL}$ of liquid LB medium supplemented with $50 \mu \mathrm{g} / \mathrm{mL}$ kanamycin and $35 \mu \mathrm{g} / \mathrm{mL}$ chloramphenicol and allowed to grow for $\sim 16 \mathrm{~h}$ at $37^{\circ} \mathrm{C}$ with shaking $(150 \mathrm{rpm})$. The resulting starter cultures were used to inoculate $1 \mathrm{~L}$ of Terrific Broth medium in baffled shake flasks containing $50 \mu \mathrm{g} / \mathrm{mL}$ kanamycin and left at $37^{\circ} \mathrm{C}$ under 
agitation until the culture optical density reached an $\mathrm{OD}_{600}$ of $\sim 1.0$. Cultures were then cooled to $18{ }^{\circ} \mathrm{C}$ for $\sim 0.5 \mathrm{~h}$, and Isopropyl $\beta$-D-1-thiogalactopyranoside (IPTG) was added to the medium (at $0.65 \mathrm{mM}$ final concentration). Cells were allowed to grow for $\sim 16 \mathrm{~h}$ under agitation $(150 \mathrm{rpm})$ at $18{ }^{\circ} \mathrm{C}$ and harvested by centrifugation for $15 \mathrm{~min}$ at 7,500×g at $4{ }^{\circ} \mathrm{C}$. The cell pellet was suspended in Binding buffer ( $25 \mathrm{mM}$ Tris$\mathrm{HCL}, \mathrm{pH}$ 8.0, $300 \mathrm{mM} \mathrm{NaCl}, 5 \%$ (v/v) glycerol, $1 \mathrm{mM}$ tris(2-carboxyethyl)phosphine- TCEP). Cells were lysed by sonication. Polyethyleneimine (PEI - pH 7.5) was added to the cell lysate to a final concentration of $0.15 \%(\mathrm{w} / \mathrm{v})$ and the sample was centrifuged at 53,000 $\times \mathrm{g}$ for $45 \mathrm{~min}$ at $4{ }^{\circ} \mathrm{C}$. The clarified cell lysate was loaded onto an Immobilised Metal Affinity Chromatography (IMAC) column (5 mL HisTrap FF Crude, GE Healthcare) at a flow rate of $2.5 \mathrm{~mL} \cdot \mathrm{min}^{-1}$, washed in Binding buffer supplemented with $30 \mathrm{mM}$ imidazole, and eluted in Elution buffer (Binding buffer supplemented with $300 \mathrm{mM}$ imidazole). The eluted protein was further purified using a size-exclusion column (Superdex 200 16/60, GE Healthcare), previously equilibrated in GF buffer (20 mM HEPES pH 7.5, $300 \mathrm{mM} \mathrm{NaCl}, 5 \%$ glycerol, 1mM TCEP). Fractions were analysed by SDS-PAGE and the molecular weight of the obtained protein was confirmed by Liquid Chromatography-Mass Spectrometry (LC-MS). Purified proteins were flash-frozen in a liquid nitrogen bath and kept at $-80^{\circ} \mathrm{C}$ until use.

\section{Enzymatic assays}

EcoDHFR enzymatic activity was monitored using the fluorescence generated by the enzyme-catalysed oxidation of NADPH in the presence of 7,8-dihydrofolate (diHF). All reactions were performed at $25^{\circ} \mathrm{C}$ in reaction buffer containing $50 \mathrm{mM}$ PIPES (pH 7.3), 0.05\% Tween-20, $400 \mu \mathrm{M}$ NADPH, $1.5 \mu \mathrm{M}$ Bovine Serum Albumin (BSA) and $6.0 \mu \mathrm{M}$ dithiothreitol (DTT) using flat bottom, low-volume, 384-well black plates (Corning; catalogue \#3573). Enzyme reactions were started by the addition of $500 \mu \mathrm{M} \mathrm{diHF}$ to the reaction mixture and the raw NADPH fluorescence (excitation $340 \mathrm{~nm}$ / emission $445 \mathrm{~nm}$ ) was collected using a BMG LABTECH Clariostar luminometer plate reader set on kinetic mode. To determine the optimal enzyme concentration for the assay, we followed reaction progress curves at increasing enzyme concentrations. All subsequent experiments were performed at the obtained half-maximal effective concentration $\left(E_{50}\right)$ for EcoDHFR $(10 \mathrm{nM})$ and NLuc-EcoDHFR $(13 \mathrm{nM})$. To estimate $K_{\mathrm{M}}$ and $V_{\max }$, enzyme initial velocities were plotted as a function of substrate concentration and fitted to the Michaelis-Menten model using a non-linear procedure implemented in GraphPad Prism using equation [1]:

$$
\text { Intial velocity }\left(n M \cdot \sec ^{-1}\right)=\frac{V_{\max } \times[\text { diHF }]}{\left(K_{\mathrm{M}}+[\text { diHF] }\right.}
$$


where $V_{\max }=$ maximum enzyme velocity extrapolated to very high substrate concentrations and $K_{\mathrm{M}}$ is the Michaelis-Menten constant defined as the substrate concentration needed to achieve half-maximum enzyme velocity.

To estimate half-maximal inhibitory concentration $\left(I_{C_{50}}\right)$ values, we followed reaction progress curves at increasing test compound concentrations (antibiotics, TMP-derived fluorescent tracers, and test compounds) serially-diluted in $100 \%$ DMSO and transferred to a 384 -well plate containing the reaction buffer and the appropriate enzyme using a CyBio FeliX liquid handler (Analytik Jena, Jena, Germany) (final DMSO concentrations in the assay were either $0.06 \%$ or $0.33 \%$ ). Plates were incubated at $25{ }^{\circ} \mathrm{C}$ for $1 \mathrm{~h}$ and the reaction was started by the addition of substrate diHF. Data was collected as described above. Enzyme reaction rates were plotted as a function of test compound concentration, and the data were fitted to equation [2] using a non-linear procedure in GraphPad Prism to estimate the $\mathrm{IC}_{50}$ value.

$$
\text { Enzyme reaction rate }=\text { Plateau }_{\text {bottom }}+\frac{\text { Plateau }_{\text {top }}-\text { Plateau }_{\text {bottom }}}{1+10^{\left(\log \mathrm{IC}_{50}-x\right) \times \text { Hill }}}
$$

where Hill $=$ Hill slope describing the steepness of the curve and $x=$ test compound concentration.

Obtained $\mathrm{IC}_{50}$ values were converted to inhibition constants $(\mathrm{Ki})$ using the Cheng-Prusoff formalism ${ }^{76}$.

\section{Determination of energy transfer probe affinity using BRET TE in vitro and bacterial cultures}

For in-cell BRET assays, bacteria (E. coli or M. abscessus) expressing the NLuc-fused target protein were grown in flasks containing M9 Minimal Medium supplemented with kanamycin $(50 \mu \mathrm{g} / \mathrm{mL})$ at $37^{\circ} \mathrm{C}$ with shaking $\left(160 \mathrm{rpm}\right.$ ) until cells reached an $\mathrm{OD}_{600}$ of $\sim 0.4$. For in vitro BRET assays, we used recombinant NLuc-EcoDHFR in PIPES and Tween Buffer (0.5 M PIPES, 0.2\% Tween, pH: 7.3) containing excess NADPH $(900 \mu \mathrm{M})$ at a final concentration of $15 \mathrm{pM}$. Cells or purified protein were aliquoted ( $85 \mu \mathrm{L}$ ) onto a 96 -well plate (white, flat bottom, non-binding - Greiner; catalogue \# 655083). Energy transfer probes (5 $\mu \mathrm{L}$ ) were added to cells or purified protein as a serial dilution series ( $\geq 8$ points, maximum final probe concentration of $5.0 \mu \mathrm{M}$ ). This was prepared by first diluting the concentrated probe stock solution into $100 \%$ DMSO (to 100X the final assay concentration) and then in Tracer Dilution Buffer (TDB - 12.5 mM HEPES, pH 7.5; $31.25 \%$ PEG 400) to $20 X$ the final assay concentration. The final volume of the mixture was brought to 100 $\mu \mathrm{L}$ by the addition of $10 \mu \mathrm{L}$ of either sterile M9 medium or PIPES and Tween Buffer for wells containing $E$. coli cells or purified protein, respectively. Final DMSO concentration in these assays was $1.0 \%$. Plates were incubated for $30 \mathrm{~min}$ at $25{ }^{\circ} \mathrm{C}$ and Promega cocktail containing furimazine and NanoLuc extracellular inhibitor (catalogue \# N2161) were added to each well. Light emissions at 460 $\pm 10 \mathrm{~nm}$ (BRET donor) and at $610 \pm 20 \mathrm{~nm}$ (BRET acceptor) were sequentially recorded (integration time $=0.5 \mathrm{~s}$, gain $=3600$ ) using a 
luminometer (BMG LABTECH Clariostar). Raw BRET values were calculated by dividing the acceptor luminescence by the donor luminescence. These are reported as milli-BRET (mBRET) units (mBU), according to equation [3]:

$$
\text { mBRET }=\left(\frac{\text { Acceptor }_{\text {sample }}}{\text { Donor }_{\text {sample }}}\right) \times 1,000
$$

BRET values were converted to a blank-corrected probe occupancy (\%) according to equation [4]:

$$
\text { Probe occupancy }(\%)=\frac{X-Z}{Y-Z} \times 100
$$

where $X=$ mBRET value in the presence of the test compound and the probe, $Y=m$ BRET value in the presence of probe only, and $Z=m B R E T$ value in the absence of probe and test compound.

To determine apparent dissociation constants from saturation binding curves, probe occupancy (\%) values were plotted as a function of probe concentration, and values for probe equilibrium dissociation constants $\left(K_{d}\right)$ were determined using the hyperbolic dose-response equation [5] for binding to a single site available in GraphPad Prism:

$$
\text { Probe occupancy }(\%)=\frac{\mathrm{B}_{\max } \times[\text { Probe }]}{\left(K_{d}+[\text { Probe }]\right)}
$$

where $B_{\max }=$ maximum specific binding extrapolated to very high probe concentrations.

\section{Determination of test compound binding potency using BRET TE in vitro and bacterial}

\section{cultures}

To determine test compound binding potency for NLuc-fused target in living bacterial cells and in vitro, probes were added to cells or purified protein at a fixed, saturating concentration as indicated in the text. Excess EcoDHFR cofactor NADPH was added to all in vitro experiments. Cells (E. coli or M. abscessus), purified protein and energy transfer probes were prepared as above. Test compounds $(10 \mu \mathrm{L})$ were added to cells or purified protein as serial dilution series ( $\geq 8$ points). These were prepared by first diluting test compound stock solutions to $1,000 \mathrm{X}$ the final assay concentration in $100 \%$ DMSO, then further diluting these solutions to 10X the final assay concentration in either sterile M9 medium or PIPES and Tween Buffer for wells containing E. coli cells or purified protein, respectively. Final concentration of DMSO in these assays was $1.0 \%$. To determine test compound concentration that yielded half-maximal response $\left(E_{50}\right)$, probe occupancy (\%) values were plotted as a function of test compound concentration, and the data were fitted to the sigmoidal dose-response equation [6] available in GraphPad Prism: 


$$
\text { Probe occupancy }(\%)=\text { Plateau }_{\text {bottom }}+\frac{\text { Plateau }_{\text {top }}-\text { Platea }_{\text {bottom }}}{1+10^{\left(x-\log \mathrm{EC}_{50}\right)}}
$$

where $x=$ test compound concentration. Obtained $\mathrm{EC}_{50}$ values were converted to inhibitor binding constants $\left(K_{\mathrm{d} A}\right)$ using the Cheng-Prusoff formalism ${ }^{76}$, according to equation [7] available in GraphPad Prism:

$$
\log \mathrm{EC}_{50}=\log \left(10^{\log K_{\mathrm{d} A} \times\left(1+\frac{[\text { Probe }]}{K_{\mathrm{d}}}\right)}\right)
$$

where [Probe] is the final concentration of BRET probe in the assay and $K_{\mathrm{d}}$ the probe equilibrium dissociation constant to the NLuc-fused target.

\section{Determination of test compound residence time using BRET TE in bacterial cultures}

To determine test compound on-target residence time in living bacterial cells ( $\left.\tau_{\text {incell }}\right), E$. coli cultures expressing the NLuc-fused target protein were cultivated in M9 medium at $37{ }^{\circ} \mathrm{C}$ with shaking (160 rpm) to an $\mathrm{OD}_{600} \sim 0.7$. Cells $(0.9 \mathrm{~mL})$ were transferred to a 24-well plate and diluted with the same volume of pre-warmed M9 minimal media. Test compounds ( $200 \mu \mathrm{L}$ at $10 \mathrm{x}$ the final desired concentration, prepared as above) were added to the cells, the plate was sealed with a breathable film and the mixture incubated for $1 \mathrm{~h}$ at $37^{\circ} \mathrm{C}$ under agitation. Cells $(0.5 \mathrm{~mL})$ were transferred to plastic tubes, collected by centrifugation $(3,000 \mathrm{xg}, 5 \mathrm{~min})$ and suspended in the same volume of sterile, pre-warmed M9 minimal media. Cells (0.1 $\mathrm{mL}$ ) were transferred to a 96 -well, flat-bottom, non-binding plate as above. $0.1 \mathrm{~mL}$ of a $2 \mathrm{x}$-concentrated cocktail containing NLuc substrate, NLuc extracellular inhibitor and TMP-590 (final assay concentration was $1.0 \mu \mathrm{M}$, prepared as above) were added to wells with cells immediately before starting the BRET signal data collection. Kinetic measurements were collected every two minutes for a total time of two hours (60 cycles) using a BMG LABTECH Clariostar luminometer as described above. Raw BRET values were calculated and transformed to blank-corrected probe occupancy (\%) values as described above.

To determine test compound residence time in bacteria, probe occupancy (\%) values were plotted as a function of time. The observed association rate constant ( $\left.K_{\text {obs-incell }}\right)$ of the TMP-590 in the control (no compound) samples was obtained by data fitting to the one-phase association equation [8] available in GraphPad Prism:

$$
\text { Probe Occupancy }(\%)=\text { Plateau }_{\text {bottom }}+\left(\left(\text { Plateau }_{\text {top }}-\text { Plateau }_{\text {bottom }}\right) \times\left(1-e^{\left(-K_{\text {obs-incell }} \cdot t\right)}\right)\right)
$$

where $t=$ time. The obtained $K_{\text {obs-incell }}$ values were used to estimate dissociation rate constant of test compounds in bacteria ( $k_{\text {off-incell }}$ ) by global data fitting to the competitor washout kinetics equation [9] first 
derived by Hoare and colleagues ${ }^{56,57}$. Equation [9] below is also available as a GraphPad Prism equation from the Pharmechanics website (https://www.pharmechanics.com/curve-fitting):

$$
\begin{aligned}
& \text { Probe Occupancy }(\%) \\
& =\text { Plateau }_{\text {bottom }} \\
& +\left(\text { Plateau }_{t o p}-\text { Plateau }_{\text {bottom }}\right) \\
& \\
& \times\left(1-\left(1-\frac{0.01 \cdot I P O \cdot k_{o b s}}{k_{o b s}-k_{o f f}}\right) e^{-k_{o b s} \cdot t}-\frac{0.01 \cdot I P O \cdot k_{o b s}}{k_{o b s}-k_{o f f}} e^{-k_{o f f} \cdot t}\right)
\end{aligned}
$$

where IPO is the initial percent occupancy of NLuc-fused target by the test compound before adding the BRET tracer; $k_{\mathrm{obs}}$ is the observed association rate of the BRET tracer in the absence of a test compound ( $\left.K_{\text {obs-incell }}\right)$ and $k_{\text {off }}$ is the dissociation rate constant of test compounds in bacteria ( $\left.k_{\text {off-incell }}\right)$.

\section{Bacterial viability assays}

Bacterial cells were grown overnight in M9 Minimal Medium and diluted to an $\mathrm{OD}_{600}$ value of 0.005 in fresh media. For Minimum Inhibitory Concentration (MIC) assessments, compounds were serially diluted in $100 \%$ DMSO and $1.0 \mu \mathrm{L}$ of each dilution point was transferred to the test plate containing $99 \mu \mathrm{L}$ of the diluted overnight bacterial culture. Plates were incubated at $37{ }^{\circ} \mathrm{C}$ without shaking for $24 \mathrm{~h}$. Then, $10 \mu \mathrm{L}$ of alamarBlue was added to the samples and incubated for $1 \mathrm{~h}$. The fluorescence intensity of each sample was measured in a BMG LABTECH Clariostar luminometer (excitation $560 \mathrm{~nm} /$ emission $590 \mathrm{~nm}$ ) and used to calculate cell viability (\%) compared to a (vehicle only) control. These values were plotted versus test compound concentration. MIC values were based on the extrapolation of a tangent from the inflexion point of a fitted Gompertz curve to the zero-growth line ${ }^{36}$, as calculated from a non-linear fitting procedure in GraphPad Prism using equation [8]:

$$
y(\text { cell viability, } \%)=A+C e^{-e^{B(x-M)}}
$$

where $\mathrm{A}=$ lower asymptote of $y$ (approximately zero), $\mathrm{B}=$ slope, $\mathrm{C}=$ span between upper and lower $y$ asymptotes (approximately 100) and $M=\log$ concentration of the inflexion point. The value of MIC is defined as the intersection of the line $y=A$, with the equation of the line tangential to the point $\left(M,\left(A+C e^{-}\right.\right.$ $\left.{ }^{1}\right)$ ) and calculated from a non-linear fitting procedure in GraphPad Prism using equation [9]:

$$
\mathrm{MIC}=10^{\left(\mathrm{M}+\frac{1}{\mathrm{~B}}\right)}
$$

For the identification of compounds from the library of Mycobacterial DHFR inhibitors (175 compounds), cells were cultivated as above and test compounds were added to a final concentration of $10 \mu \mathrm{M}$. \% cell 
viability for each test compound was obtained using the no growth (Ampicillin at $10.0 \mathrm{mg} / \mathrm{mL}$ ) and no drug (100\% growth) controls.

\section{Synthesis and characterization of TMP-590 and TMP-590IMP}

To generate TMP-590 and TMP-590IMP, we first modified trimethoprim (TMP; Sigma-Aldrich; catalogue \#T7883) to remove its methyl group at the benzene para position. This step was performed as previously reported ${ }^{77}$. Briefly, $1.45 \mathrm{~g}(5 \mathrm{mmol})$ of TMP was dissolved in $48 \% \mathrm{HBr}(20 \mathrm{~mL})$ at room temperature. The mixture was stirred at $100{ }^{\circ} \mathrm{C}$ for $30 \mathrm{~min}$, and then quenched with $50 \% \mathrm{NaOHaq}(15 \mathrm{~mL})$. The crude product was purified using flash chromatography (mobile phase hexane/AcOEt 50:50). ${ }^{1} \mathrm{H}$ NMR (500 MHz, DMSO) $\delta 8.22(\mathrm{~s}, 1 \mathrm{H}), 7.79(\mathrm{~s}, 2 \mathrm{H}), 7.37(\mathrm{~s}, 1 \mathrm{H}), 7.29(\mathrm{~s}, 2 \mathrm{H}), 6.55(\mathrm{~s}, 2 \mathrm{H}), 3.72(\mathrm{~s}, 6 \mathrm{H})$.

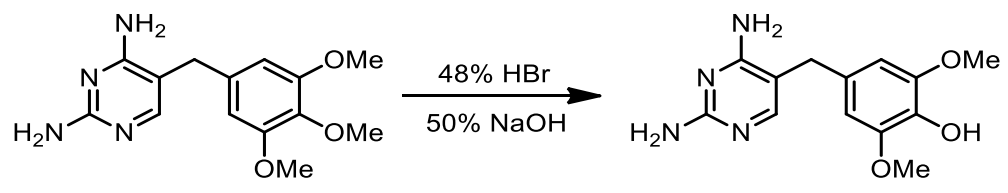

Proton NMR spectra for de-methylated TMP - solvent and magnetic field used are shown in parenthesis:
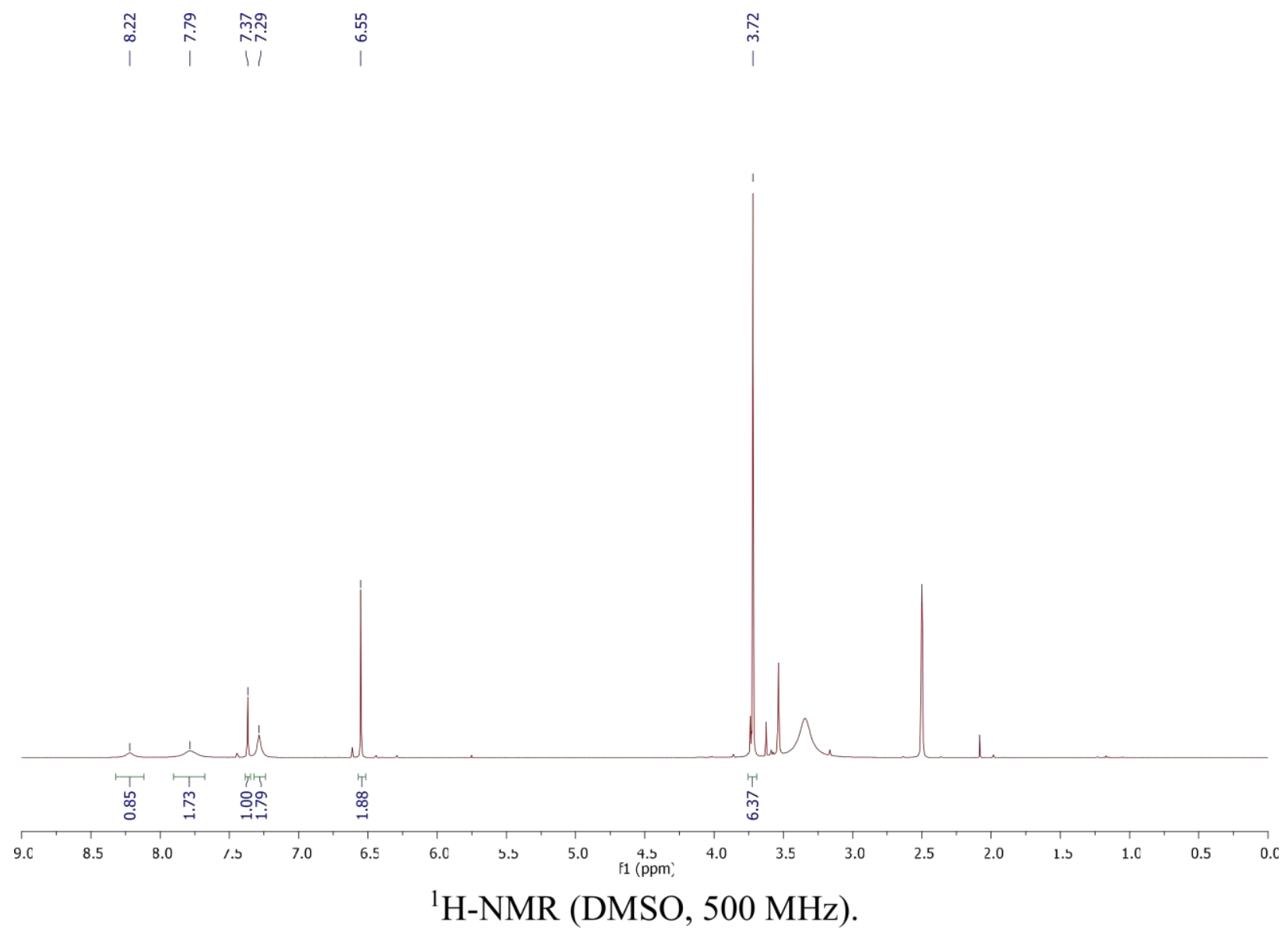
To generate the linker for both TMP-590 and TMP-590IMP, 3-Bromopropylamine (13.70 mmol, $3.0 \mathrm{~g})$ was dissolved in $80 \mathrm{~mL}$ of dichloromethane (DCM). After addition of triethylamine (16.4 mmol, $2.32 \mathrm{~mL})$ and di-tert-butylcarbonate $(13.70 \mathrm{mmol}, 3.0 \mathrm{~g})$, the resulting mixture was stirred at room temperature overnight. Then, it was washed with $2 \times 60 \mathrm{~mL}$ of a citric acid solution (5\%) and $50 \mathrm{~mL}$ of saturated brine solution. The organic fraction was dried over magnesium sulphate and concentrated to give the desired product as yellow oil of sufficient purity for use without purification in the next step. ${ }^{1} \mathrm{H} N M R(400 \mathrm{MHz}$, $\left.\mathrm{CDCl}_{3}\right) \delta 4.73(\mathrm{~s}, 1 \mathrm{H}), 3.44(\mathrm{t}, J=6.5 \mathrm{~Hz}, 2 \mathrm{H}), 3.27(\mathrm{dd}, J=12.5,6.2 \mathrm{~Hz}, 2 \mathrm{H}), 2.12-1.99(\mathrm{~m}, 2 \mathrm{H}), 1.45(\mathrm{~s}, 9 \mathrm{H})$.

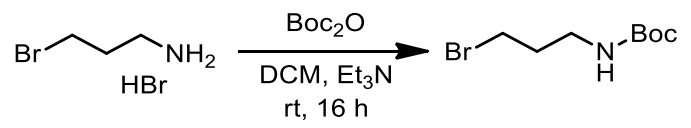


Proton NMR spectra for the linker moiety - solvent and magnetic field used are shown in parenthesis:
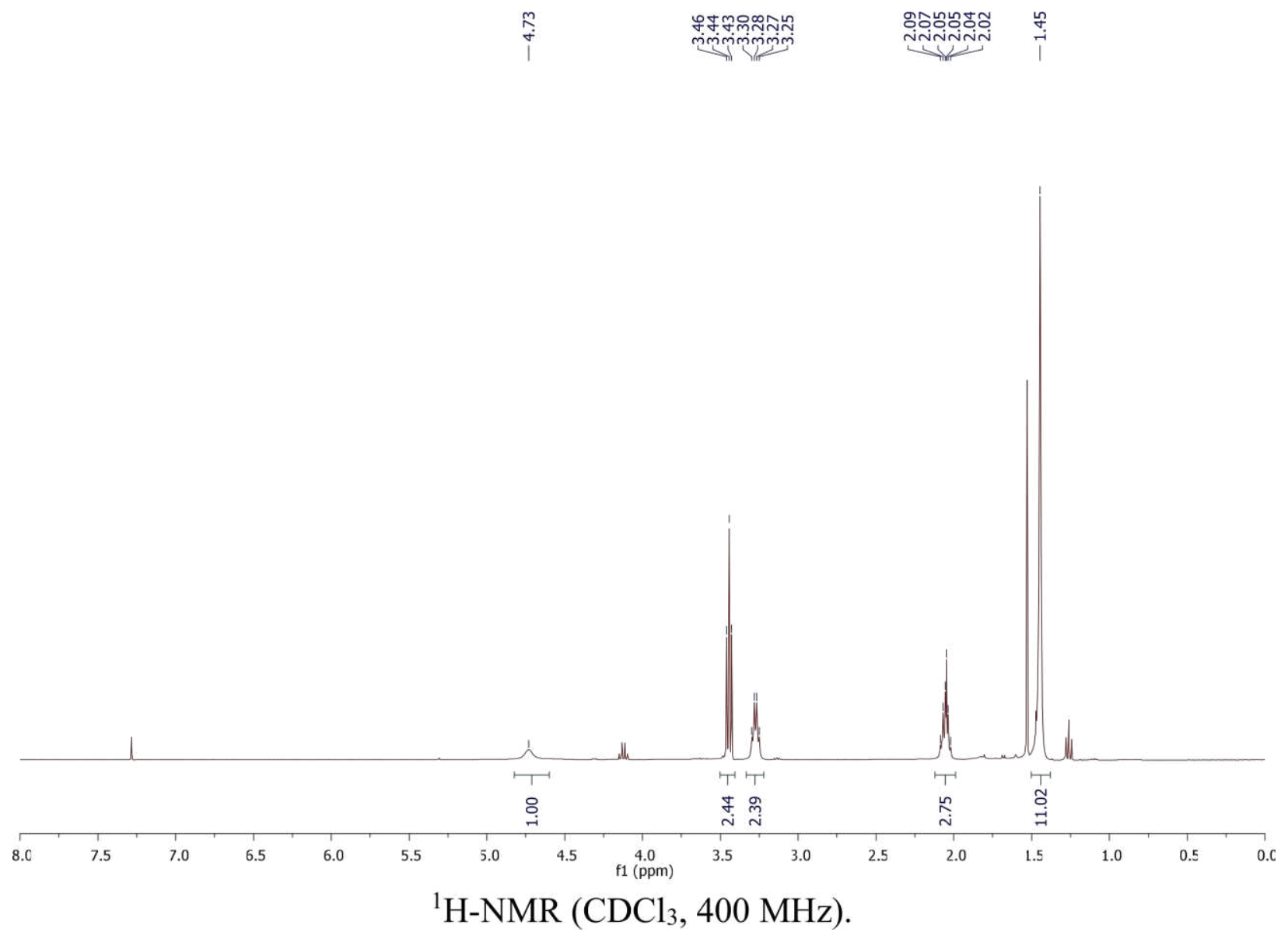
To appended the above-generated linker to TMP, $200 \mathrm{mg}(0.724 \mathrm{mmol})$ of the intermediate-OH was first dissolved in $3.6 \mathrm{ml} \mathrm{DMF} \mathrm{in} \mathrm{a} \mathrm{50-ml} \mathrm{round-bottomed} \mathrm{flask} \mathrm{and} \mathrm{then} 500 \mathrm{mg} \mathrm{K}{ }_{2} \mathrm{CO}_{3}$ (3.62 mmol) and $355 \mathrm{mg}$ 3-(Boc-amino)propyl bromide $(1.5 \mathrm{mmol})$ were added to the mixture. The reaction was heated at $70{ }^{\circ} \mathrm{C}$ in an oil bath under $\mathrm{N}_{2}$ for $5 \mathrm{hr}$ while stirring, during which the solution may turn slightly brown. After cooling to room temperature, the reaction mixture was extracted with $100 \mathrm{ml}$ brine and ethyl acetate $(3 \times 40 \mathrm{ml})$. The organic phase was combined; dried over $\mathrm{Na}_{2} \mathrm{SO}_{4}$ and ethyl acetate was removed by rotary evaporation. The crude product was purified by flash chromatography (EtOH/DCM, 1:10 v/v over silica gel) to yield pure compound. ${ }^{1} \mathrm{H}$ NMR (400 MHz, DMSO) $\delta 7.51(\mathrm{~s}, 1 \mathrm{H}), 6.74(\mathrm{t}, J=5.4 \mathrm{~Hz}, 1 \mathrm{H}), 6.55(\mathrm{~s}, 2 \mathrm{H})$, $6.10(\mathrm{~s}, 2 \mathrm{H}), 5.69(\mathrm{~s}, 2 \mathrm{H}), 3.80(\mathrm{t}, J=6.2 \mathrm{~Hz}, 2 \mathrm{H}), 3.72(\mathrm{~s}, 6 \mathrm{H}), 3.52(\mathrm{~s}, 2 \mathrm{H}), 3.09(\mathrm{dd}, J=12.8,6.6 \mathrm{~Hz}, 2 \mathrm{H})$, $1.75-1.66(\mathrm{~m}, 2 \mathrm{H}), 1.38(\mathrm{~s}, 9 \mathrm{H})$.

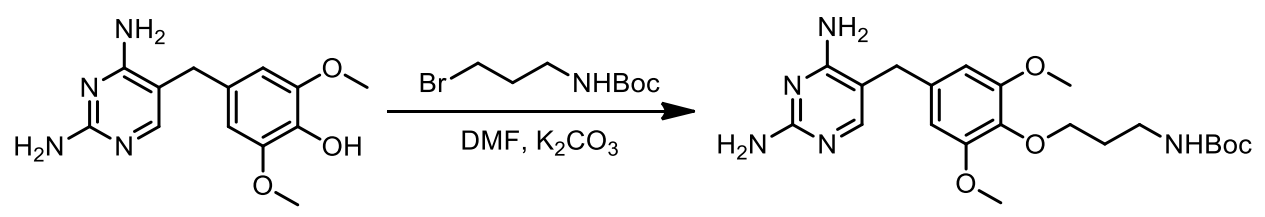


Proton NMR spectra for the TMP-linker intermediate - solvent and magnetic field used are shown in parenthesis:

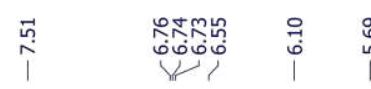

i̊ำ

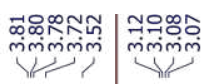

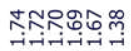
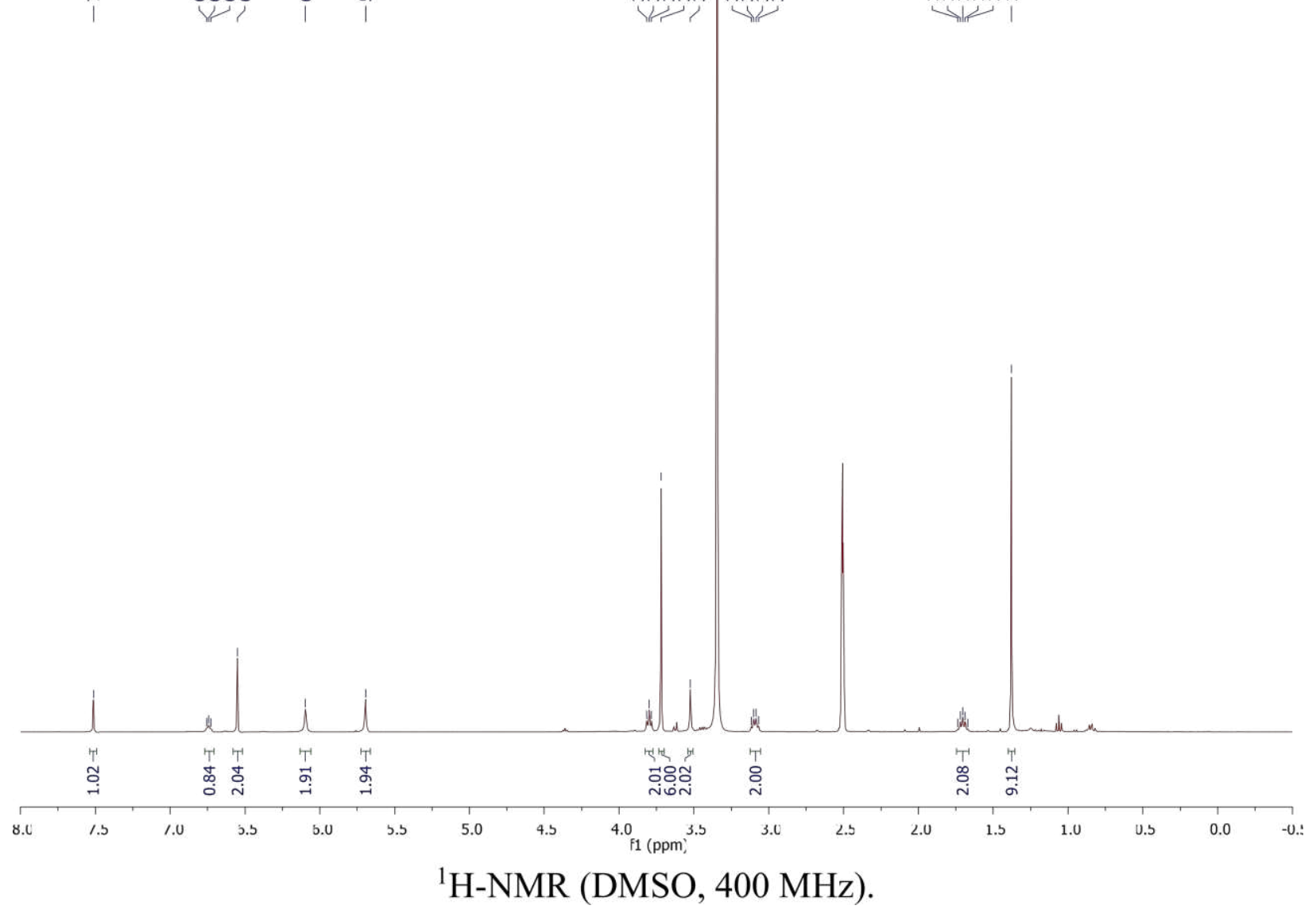
The compound $N$-Boc starting material $(62 \mathrm{mg}, 0.143 \mathrm{mmol}$ ) was dissolved in $5 \mathrm{~mL}$ of DCM and TFA ( $5 \mathrm{~mL}$ ) was added. The mixture was capped and stirred for $5 \mathrm{hr}$. Volatiles were removed under reduced pressure giving a yellow oil and $5 \mathrm{~mL}$ of diethyl ether was added giving a white precipitate. The ether was decanted and an additional $5 \mathrm{~mL}$ portion was added. The suspension was sonicated and the ether was decanted. The resulting residue was dried under high vacuum overnight affording the salt product as a white solid (quantitative yields). The crude product was directly subjected to subsequent transformation without further purification. LCMS: $\mathrm{m} / \mathrm{z}[\mathrm{M}]+1=334.2$.<smiles>COc1cc(Cc2cnc(N)nc2N)cc(OC)c1OCCCNC(=O)OCc1cc(Cc2ccccc2)c(N)nc1N</smiles>

To generate TMP-590, $\mathrm{N}$ - $\mathrm{N}$-diisopropylethylamine (DIPEA; $2.5 \mu \mathrm{L}, 14.4 \mu \mathrm{mol}$ ) was added to a stirred solution of the free amine $(1.3 \mathrm{mg}, 2.9 \mu \mathrm{mol})$, in anhydrous DMF $(1 \mathrm{~mL})$. The mixture was stirred for 10 min, NanoBRET 590 SE (Setareh Biotech; catalogue \#7365) (1.1 mg, $2.7 \mu \mathrm{mol}$ ) was added, and the reaction mixture was capped and stirred in the dark overnight under $\mathrm{N}_{2}$. The crude product was purified by flash chromatography (10\% methanol in dichloromethane) affording compound TMP-590 as a purple film (1.2 $\mathrm{mg}, 64 \%$ yield). ${ }^{1} \mathrm{H} \mathrm{NMR}\left(500 \mathrm{MHz}, \mathrm{CDCl}_{3}\right) \delta 7.71(\mathrm{~s}, 1 \mathrm{H}), 7.12(\mathrm{~s}, 1 \mathrm{H}), 7.02(\mathrm{~d}, J=4.5 \mathrm{~Hz}, 1 \mathrm{H}), 6.97(\mathrm{~s}, 1 \mathrm{H})$, $6.95(\mathrm{~s}, 1 \mathrm{H}), 6.85(\mathrm{~d}, J=4.5 \mathrm{~Hz}, 1 \mathrm{H}), 6.81(\mathrm{~d}, J=3.9 \mathrm{~Hz}, 1 \mathrm{H}), 6.78(\mathrm{t}, J=5.3 \mathrm{~Hz}, 1 \mathrm{H}), 6.38-6.35(\mathrm{~m}, 1 \mathrm{H})$, $6.33(\mathrm{~s}, 2 \mathrm{H}), 6.30(\mathrm{~d}, J=3.9 \mathrm{~Hz}, 1 \mathrm{H}), 5.02(\mathrm{~s}, 2 \mathrm{H}), 4.62(\mathrm{~s}, 2 \mathrm{H}), 3.99(\mathrm{t}, J=5.5 \mathrm{~Hz}, 2 \mathrm{H}), 3.75(\mathrm{~s}, 6 \mathrm{H}), 3.54$ (dd, $J=11.9,5.9 \mathrm{~Hz}, 2 \mathrm{H}), 3.35(\mathrm{t}, J=7.7 \mathrm{~Hz}, 2 \mathrm{H}), 2.66-2.60(\mathrm{~m}, 2 \mathrm{H}), 1.90(\mathrm{dt}, J=11.5,5.7 \mathrm{~Hz}, 2 \mathrm{H}) . \mathrm{MS}(\mathrm{ESI})$ : calculated for $\mathrm{C}_{32} \mathrm{H}_{36} \mathrm{BF}_{2} \mathrm{~N}_{8} \mathrm{O}_{4}[\mathrm{M}+\mathrm{H}]^{+}$: 645.2921. Found: 645.2938.<smiles>COc1cc(Cc2cnc(N)nc2N)cc(OC)c1OCCCNC(=O)CCC1=[R5]2(F)c(cc3ccc(-c4ccc[nH]4)n32)C=C1</smiles> 
Proton NMR spectra for the final TMP-590 probe - solvent and magnetic field used are shown in parenthesis:

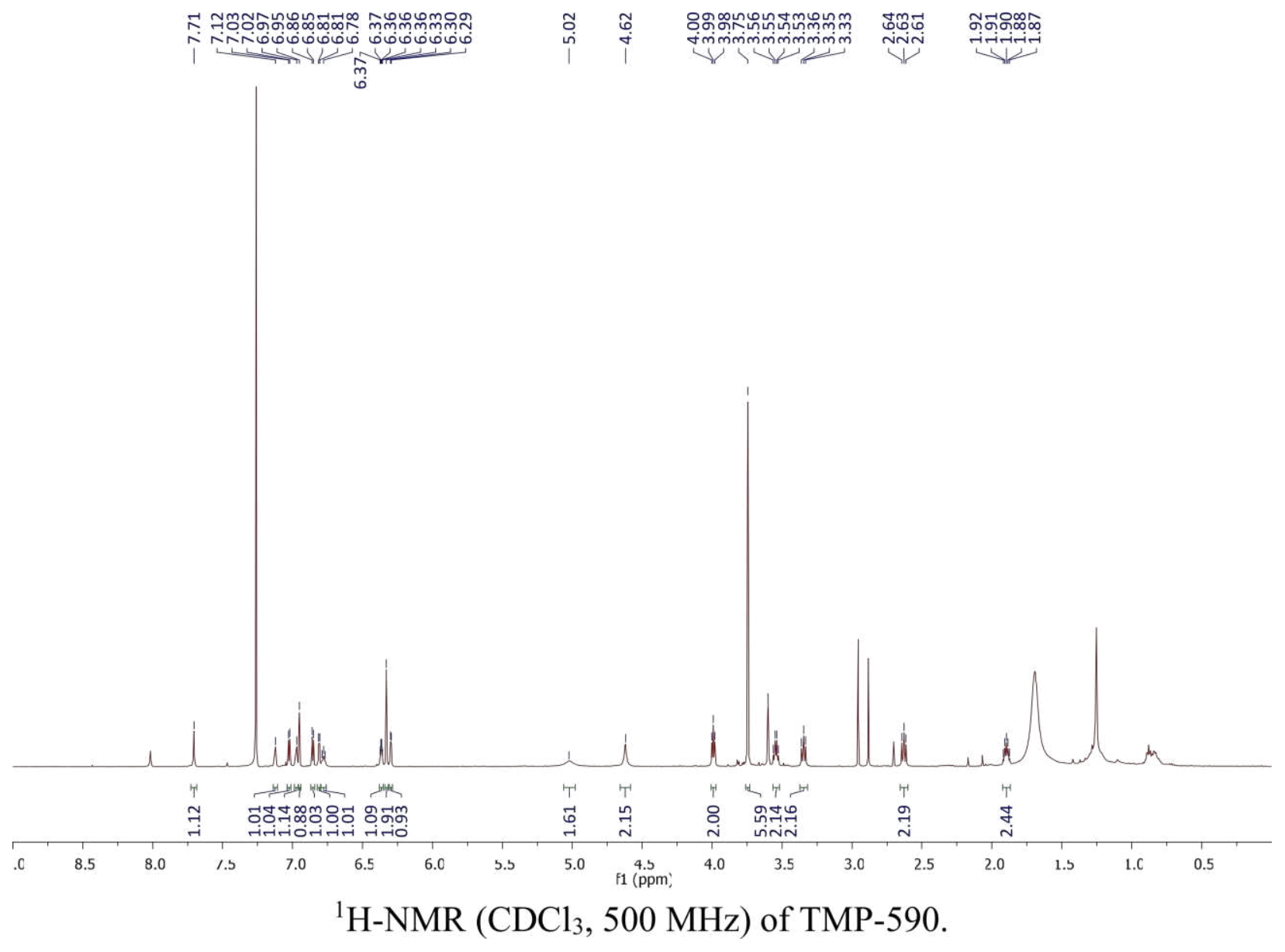


Mass Spectrometry analysis for final TMP-590:

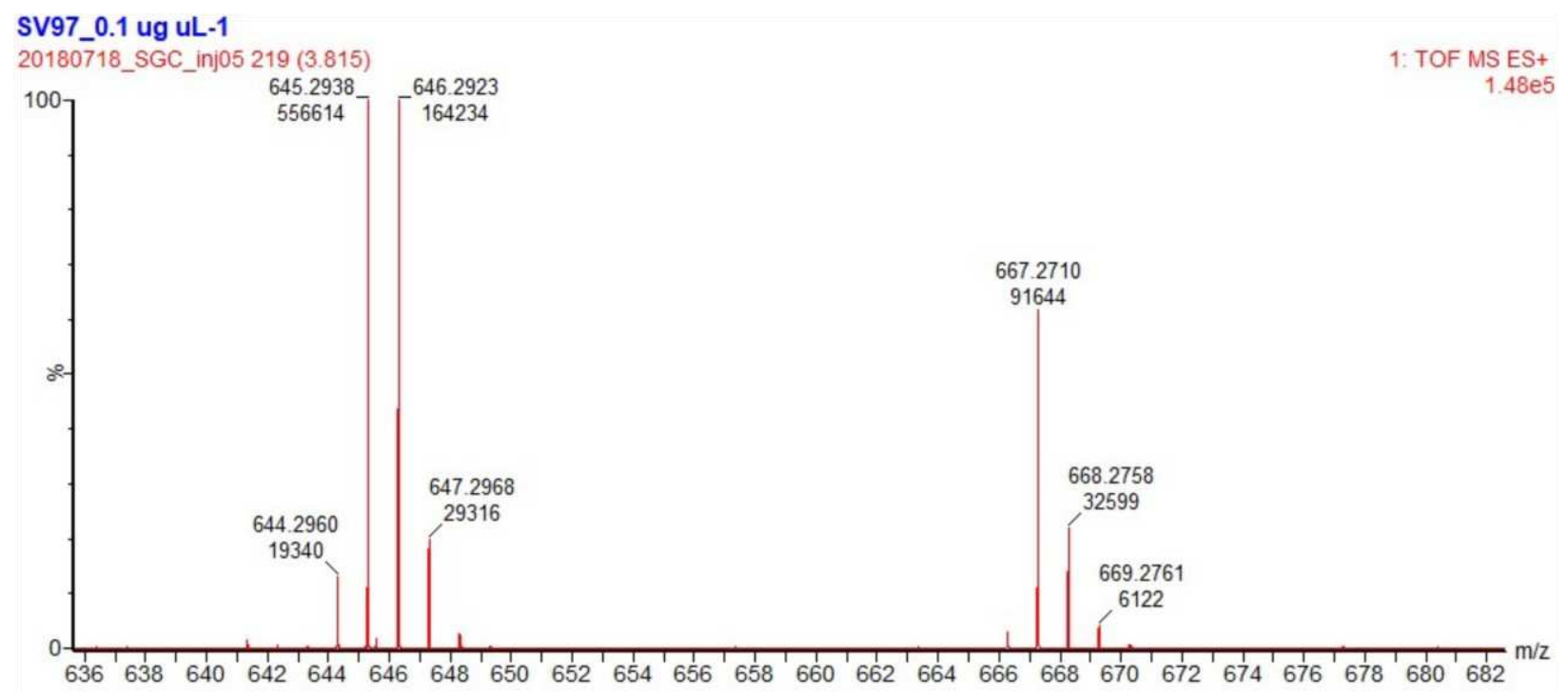

To generate TMP-590IMP, DIPEA $(5.22 \mu \mathrm{L}, 0.03 \mathrm{mmol})$ was added to a stirred solution of free amine (1.30 $\mathrm{mg}, 3.9 \mu \mathrm{mol}$ ) in DMF (385 $\mu \mathrm{L})$. The mixture was stirred for 5 minutes. DY-605-NHS-Ester (Dyomics; catalogue \#605-01) (3.33 mg, $3.0 \mu \mathrm{mol}$ ) was added, and the reaction mixture was capped and stirred in the dark for 16 hours under $\mathrm{N}_{2}$. The crude product was purified by reverse phase flash chromatography $\left.\left(\mathrm{CH}_{3} \mathrm{CN} / \mathrm{H}_{2} \mathrm{O}\right)\right)$. The compound TMP-590IMP was isolated as a blue film (3.8 $\mathrm{mg}, 98 \%$ yield). MS (ESI): calculated for $\left[\mathrm{C}_{61} \mathrm{H}_{76} \mathrm{~N}_{8} \mathrm{O}_{16} \mathrm{~S}_{4}\right]+[2 \mathrm{H}]^{+}:$1307.4491. Found 1307.4355.

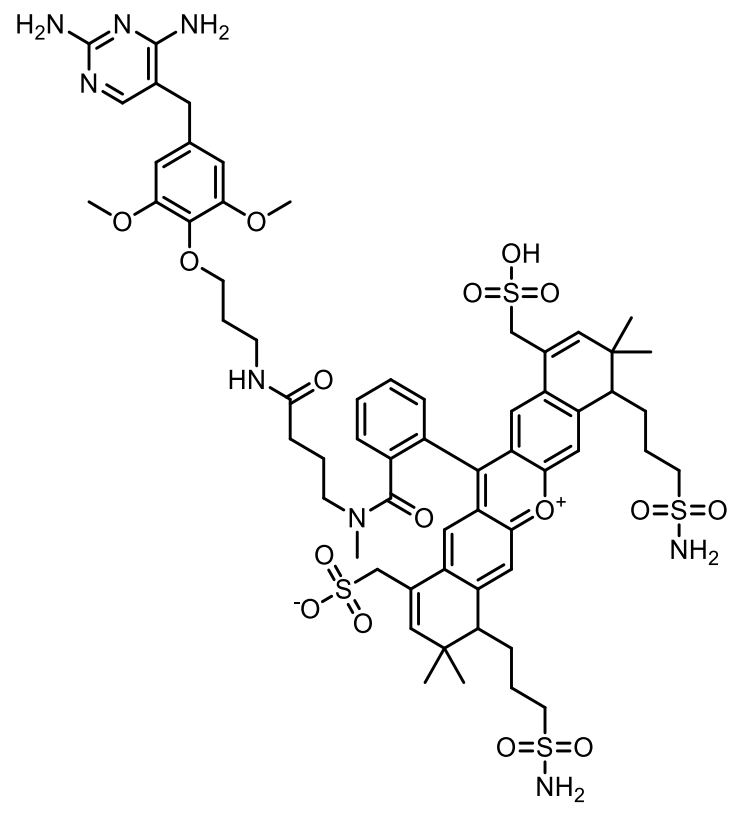


Mass Spectrometry analysis for TMP-590IMP:

SV325_0.01ug.uL-1

20191129_SGC_Stanley_SV325 191 (3.328)

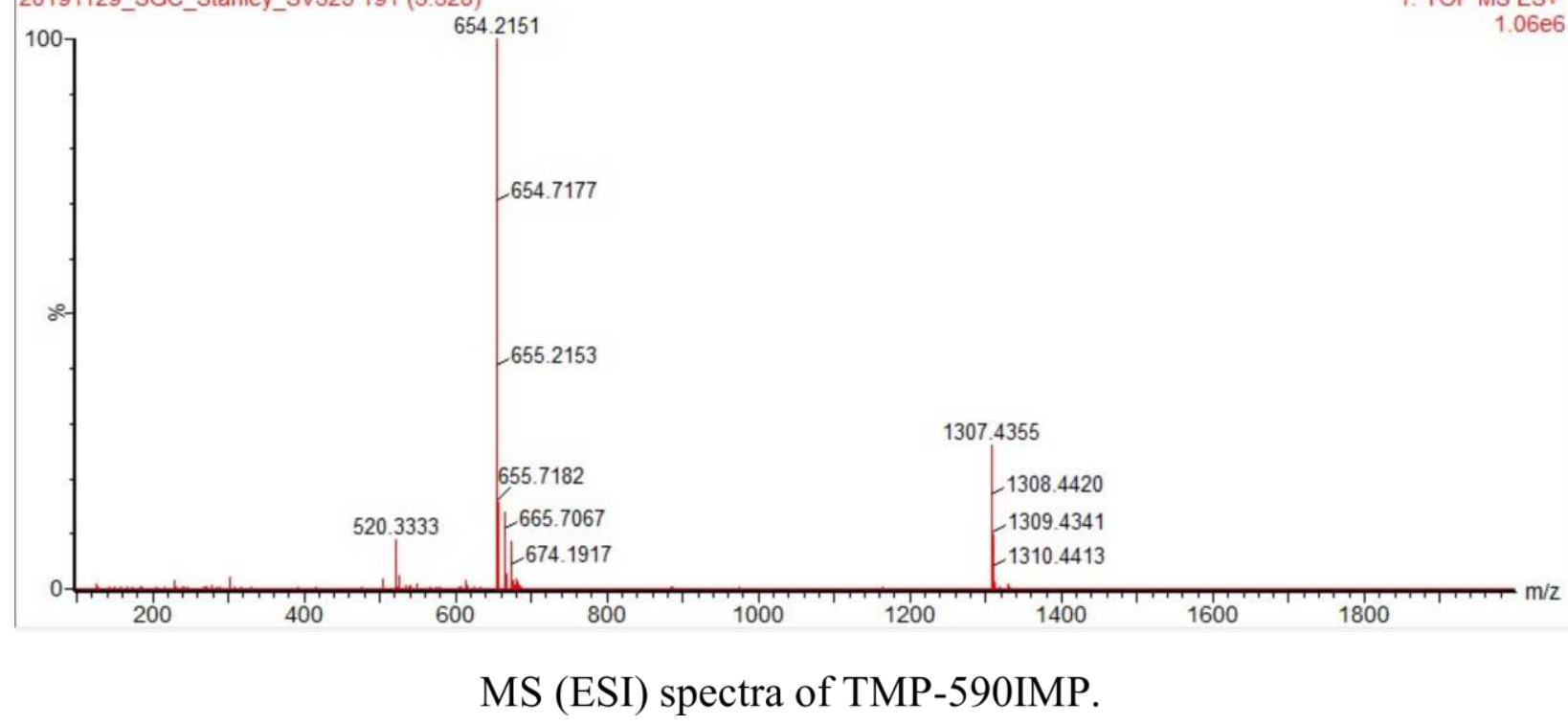




\section{Ancillary Information}

\section{Supporting Information}

Table S1: Oligonucleotide sequences; Figure S1: Recombinant production of NLuc-EcoDHFR; FigureS2: Methotrexate is equipotent towards wild-type and NLuc-fused EcoDHFR in vitro; Figure S3: Characterization of the BRET-based TE assay based on TMP-590 and NLuc-EcoDHFR; Figure S4: Binding of bulkier BRET probe TMP-IMP590 to NLuc-EcoDHFR is greatly reduced in E. coli cells compared to in vitro; Figure S5: In-cell binding constants ( $\left.\mathrm{K}_{\mathrm{d} \text {-incell }}\right)$ reflect the potency of a ligand for its molecular target in vitro; Figure S6: Impact of TolC-dependent efflux in E. coli viability and TE assays; Figure S7: Expression of NLucEcoDHFR in E. coli with and without efflux pumps result in similar and stable background BRET levels; Supplementary references.

\section{Corresponding Author Information:}

Rafael M. Couñago (rafaelcounago@gmail.com)

\section{Present/Current Author Addresses:}

S.N.S.V. - Department of Chemistry \& Biology, Ryerson University, 350 Victoria St., Toronto, ON, M5B 2K3, Canada

C.M.C.C-P - Laboratory of Parasitic Diseases, National Institute of Allergy and Infectious Diseases, National Institutes of Health, Bethesda, MD 20892, USA.

G.P.R. - Departamento de Inovação, Eurofarma Laboratórios S.A., R. Brito Peixoto, 554 - Brooklin, São Paulo - SP, 04582-020, Brazil

\section{Author Contributions}

R.C.F and S.N.S.V contributed equally.

R.C.F. designed, performed and analyzed in vitro and in-cell BRET-based assays and MIC experiments in $E$. coli and M. abscessus. G.P.R and C.V.R designed, performed, and analyzed all enzymatic assays. S.N.S.V. designed, synthesized and characterized TMP-based BRET probes. C.M.C.C-P and P.Z.R. performed and analyzed in vitro and in-cell BRET-based assays. P.Z.R. performed and analyzed in vitro BRET-based assays. J.R.S. designed, performed and analyzed in-cell BRET-based assays and MIC experiments in M. abscessus. M.A.B. analyzed data from M. abscessus. A.E. and R.M.C conceived the project. R.M.C. assisted designing and analyzing all experiments. R.C.F. and R.M.C wrote the manuscript. All authors revised the manuscript. 


\section{Acknowledgments}

We thank all members of CQMED-UNICAMP for their help and support. This work was supported by FAPESP (Fundação de Amparo à Pesquisa do Estado de São Paulo) (2013/50724-5 and 2014/50897-0), Embrapii (Empresa Brasileira de Pesquisa e Inovação Industrial), CNPq (Conselho Nacional de Desenvolvimento Científico e Tecnológico) (465651/2014-3) and The Structural Genomics Consortium, a registered charity (number 1097737). R.C.F was the recipient of a CAPES (Coordenação de Aperfeiçoamento de Pessoal de Nível Superior) M.Sc. fellowship (130075/2020-5); S.N.S.V. was the recipient of a FAPESP post-doctoral fellowship (2018/09475-5); C.M.C.C-P fellowship was in part funded by Promega Corporation; C.V.R was the recipient of a CAPES post-doctoral fellowship (88887.146077/2017-00). J.R.S and M.A.B were funded by Cystic Fibrosis Canada. We thank the staff of the Proteomics section of the Life Sciences Core Facility (LaCTAD), part of the University of Campinas (UNICAMP). We thank Matthew Robers and Samuel Hoare for critical review of the manuscript.

\section{Competing Interests Statement}

R.C.F, S.N.S.V., C.M.C.C-P, J.R.S., G.P.R., C.V.R, P.Z.R, A.E., M.A.B \& R.M.C. declare no competing financial interest.

\section{References}

(1) Zgurskaya, H. I.; López, C. A.; Gnanakaran, S. Permeability Barrier of Gram-Negative Cell Envelopes and Approaches to Bypass It. ACS Infectious Diseases 2016, 1 (11), 512-522. https://doi.org/10.1021/acsinfecdis.5b00097.

(2) Nikaido, H. Molecular Basis of Bacterial Outer Membrane Permeability Revisited. Microbiology and Molecular Biology Reviews 2003, 67 (4), 593-656. https://doi.org/10.1128/mmbr.67.4.593656.2003.

(3) Vergalli, J.; Bodrenko, I. v.; Masi, M.; Moynié, L.; Acosta-Gutiérrez, S.; Naismith, J. H.; Davin-Regli, A.; Ceccarelli, M.; van den Berg, B.; Winterhalter, M.; Pagès, J. M. Porins and Small-Molecule Translocation across the Outer Membrane of Gram-Negative Bacteria. Nature Reviews Microbiology 2020, 18 (3), 164-176. https://doi.org/10.1038/s41579-019-0294-2.

(4) Webber, M. A.; Piddock, L. J. v. The Importance of Efflux Pumps in Bacterial Antibiotic Resistance. Journal of Antimicrobial Chemotherapy 2003, 51 (1), 9-11. https://doi.org/10.1093/JAC/DKG050. 
(5) Luthra, S.; Rominski, A.; Sander, P. The Role of Antibiotic-Target-Modifying and AntibioticModifying Enzymes in Mycobacterium Abscessus Drug Resistance. Frontiers in Microbiology 2018, 9 (SEP). https://doi.org/10.3389/fmicb.2018.02179.

(6) Payne, D. J.; Gwynn, M. N.; Holmes, D. J.; Pompliano, D. L. Drugs for Bad Bugs: Confronting the Challenges of Antibacterial Discovery. Nature Reviews Drug Discovery 2007, 6 (1), 29-40. https://doi.org/10.1038/nrd2201.

(7) Tommasi, R.; Brown, D. G.; Walkup, G. K.; Manchester, J. I.; Miller, A. A. ESKAPEing the Labyrinth of Antibacterial Discovery. Nature Reviews Drug Discovery 2015, 14 (8), 529-542. https://doi.org/10.1038/nrd4572.

(8) Hutchings, M.; Truman, A.; Wilkinson, B. Antibiotics: Past, Present and Future. Current Opinion in Microbiology. Elsevier Ltd October 2019, pp 72-80. https://doi.org/10.1016/j.mib.2019.10.008.

(9) Lewis, K. Platforms for Antibiotic Discovery. Nature Reviews Drug Discovery 2013, 12 (5), 371-387. https://doi.org/10.1038/nrd3975.

(10) Terstappen, G. C.; Schlüpen, C.; Raggiaschi, R.; Gaviraghi, G. Target Deconvolution Strategies in Drug Discovery. Nature Reviews Drug Discovery. 2007, pp 891-903. https://doi.org/10.1038/nrd2410.

(11) Johnson, E. O.; LaVerriere, E.; Office, E.; Stanley, M.; Meyer, E.; Kawate, T.; Gomez, J. E.; Audette, R. E.; Bandyopadhyay, N.; Betancourt, N.; Delano, K.; da Silva, I.; Davis, J.; Gallo, C.; Gardner, M.; Golas, A. J.; Guinn, K. M.; Kennedy, S.; Korn, R.; McConnell, J. A.; Moss, C. E.; Murphy, K. C.; Nietupski, R. M.; Papavinasasundaram, K. G.; Pinkham, J. T.; Pino, P. A.; Proulx, M. K.; Ruecker, N.; Song, N.; Thompson, M.; Trujillo, C.; Wakabayashi, S.; Wallach, J. B.; Watson, C.; loerger, T. R.; Lander, E. S.; Hubbard, B. K.; Serrano-Wu, M. H.; Ehrt, S.; Fitzgerald, M.; Rubin, E. J.; Sassetti, C. M.; Schnappinger, D.; Hung, D. T. Large-Scale Chemical-Genetics Yields New M. Tuberculosis Inhibitor Classes. Nature 2019 571:7763 2019, 571 (7763), 72-78. https://doi.org/10.1038/s41586-0191315-z.

(12) Richter, M. F.; Drown, B. S.; Riley, A. P.; Garcia, A.; Shirai, T.; Svec, R. L.; Hergenrother, P. J. Predictive Compound Accumulation Rules Yield a Broad-Spectrum Antibiotic. Nature 2017, 545 (7654), 299-304. https://doi.org/10.1038/nature22308. 
(13) Brown, D. G.; May-Dracka, T. L.; Gagnon, M. M.; Tommasi, R. Trends and Exceptions of Physical Properties on Antibacterial Activity for Gram-Positive and Gram-Negative Pathogens. Journal of Medicinal Chemistry 2014, 57 (23), 10144-10161. https://doi.org/10.1021/jm501552x.

(14) O'Shea, R.; Moser, H. E. Physicochemical Properties of Antibacterial Compounds: Implications for Drug Discovery. Journal of Medicinal Chemistry 2008, 51 (10), 2871-2878. https://doi.org/10.1021/jm700967e.

(15) Mehla, J.; Malloci, G.; Mansbach, R.; López, C. A.; Tsivkovski, R.; Haynes, K.; Leus, I. v.; Grindstaff, S. B.; Cascella, R. H.; D’cunha, N.; Herndon, L.; Hengartner, N. W.; Margiotta, E.; Atzori, A.; Vargiu, A. v.; Manrique, P. D.; Walker, J. K.; Lomovskaya, O.; Ruggerone, P.; Gnanakaran, S.; Rybenkov, V. v.; Zgurskaya, H. I. Predictive Rules of Efflux Inhibition and Avoidance in Pseudomonas Aeruginosa. mBio 2021, 12 (1), 1-19. https://doi.org/10.1128/mBio.02785-20.

(16) Nikaido, H. Prevention of Drug Access to Bacterial Targets: Permeability Barriers and Active Efflux. Science (1979) 1994, 264 (5157), 382-388. https://doi.org/10.1126/science.8153625.

(17) Nikaido, H. Molecular Basis of Bacterial Outer Membrane Permeability Revisited. Microbiology and Molecular Biology Reviews 2003, 67 (4), 593-656. https://doi.org/10.1128/mmbr.67.4.593656.2003.

(18) Durand-Reville, T. F.; Miller, A. A.; O’Donnell, J. P.; Wu, X.; Sylvester, M. A.; Guler, S.; Iyer, R.; Shapiro, A. B.; Carter, N. M.; Velez-Vega, C.; Moussa, S. H.; McLeod, S. M.; Chen, A.; Tanudra, A. M.; Zhang, J.; Comita-Prevoir, J.; Romero, J. A.; Huynh, H.; Ferguson, A. D.; Horanyi, P. S.; Mayclin, S. J.; Heine, H. S.; Drusano, G. L.; Cummings, J. E.; Slayden, R. A.; Tommasi, R. A. Rational Design of a New Antibiotic Class for Drug-Resistant Infections. Nature 2021, 597 (7878), 698-702. https://doi.org/10.1038/s41586-021-03899-0.

(19) Acosta-Gutiérrez, S.; Ferrara, L.; Pathania, M.; Masi, M.; Wang, J.; Bodrenko, I.; Zahn, M.; Winterhalter, M.; Stavenger, R. A.; Pagès, J. M.; Naismith, J. H.; van den Berg, B.; Page, M. G. P.; Ceccarelli, M. Getting Drugs into Gram-Negative Bacteria: Rational Rules for Permeation through General Porins. ACS Infectious Diseases 2018, 4 (10), 1487-1498. https://doi.org/10.1021/acsinfecdis.8b00108. 
(20) Pfleger, K. D. G.; Eidne, K. A. Illuminating Insights into Protein-Protein Interactions Using Bioluminescence Resonance Energy Transfer (BRET). Nature methods. 2006. https://doi.org/10.1038/nmeth841.

(21) Pfleger, K. D. G.; Seeber, R. M.; Eidne, K. A. Bioluminescence Resonance Energy Transfer (BRET) for the Real-Time Detection of Protein-Protein Interactions. Nature Protocols 2006. https://doi.org/10.1038/nprot.2006.52.

(22) Dacres, H.; Dumancic, M. M.; Horne, I.; Trowell, S. C. Direct Comparison of Fluorescence- and Bioluminescence-Based Resonance Energy Transfer Methods for Real-Time Monitoring of Thrombin-Catalysed Proteolytic Cleavage. Biosensors and Bioelectronics 2009. https://doi.org/10.1016/j.bios.2008.07.021.

(23) Stoddart, L. A.; Johnstone, E. K. M.; Wheal, A. J.; Goulding, J.; Robers, M. B.; MacHleidt, T.; Wood, K. v.; Hill, S. J.; Pfleger, K. D. G. Application of BRET to Monitor Ligand Binding to GPCRs. Nature Methods 2015, 12 (7), 661-663. https://doi.org/10.1038/nmeth.3398.

(24) Robers, M. B.; Dart, M. L.; Woodroofe, C. C.; Zimprich, C. A.; Kirkland, T. A.; Machleidt, T.; Kupcho, K. R.; Levin, S.; Hartnett, J. R.; Zimmerman, K.; Niles, A. L.; Ohana, R. F.; Daniels, D. L.; Slater, M.; Wood, M. G.; Cong, M.; Cheng, Y. Q.; Wood, K. v. Target Engagement and Drug Residence Time Can Be Observed in Living Cells with BRET. Nature Communications 2015, 6 (May), 10091. https://doi.org/10.1038/ncomms10091.

(25) Robers, M. B.; Vasta, J. D.; Corona, C. R.; Ohana, R. F.; Hurst, R.; Jhala, M. A.; Comess, K. M.; Wood, K. v. Quantitative, Real-Time Measurements of Intracellular Target Engagement Using Energy Transfer. Methods in Molecular Biology 2019, 1888, 45-71. https://doi.org/10.1007/978-1-49398891-4_3.

(26) Machleidt, T.; Woodroofe, C. C.; Schwinn, M. K.; Méndez, J.; Robers, M. B.; Zimmerman, K.; Otto, P.; Daniels, D. L.; Kirkland, T. A.; Wood, K. v. NanoBRET-A Novel BRET Platform for the Analysis of $\begin{array}{lllll}\text { Protein-Protein } & \text { Interactions. } & \text { ACS } & \text { Chemical }\end{array}$ https://doi.org/10.1021/acschembio.5b00143.

(27) Copeland, R. A. Conformational Adaptation in Drug-Target Interactions and Residence Time. Future Medicinal Chemistry 2011, 3 (12), 1491-1501. https://doi.org/10.4155/fmc.11.112. 
(28) Eduful, B. J.; O’Byrne, S. N.; Temme, L.; Asquith, C. R. M.; Liang, Y.; Picado, A.; Pilotte, J. R.; Hossain, M. A.; Wells, C. I.; Zuercher, W. J.; Catta-Preta, C. M. C.; Zonzini Ramos, P.; Santiago, A. D. S.; Couñago, R. M.; Langendorf, C. G.; Nay, K.; Oakhill, J. S.; Pulliam, T. L.; Lin, C.; Awad, D.; Willson, T. M.; Frigo, D. E.; Scott, J. W.; Drewry, D. H. Hinge Binder Scaffold Hopping Identifies Potent Calcium/Calmodulin-Dependent Protein Kinase Kinase 2 (CAMKK2) Inhibitor Chemotypes. Journal of Medicinal Chemistry 2021, 64 (15), 10849-10877. https://doi.org/10.1021/acs.jmedchem.0c02274.

(29) Kompis, I. M.; Islam, K.; Then, R. L. DNA and RNA Synthesis: Antifolates. Chemical Reviews. 2005, pp 593-620. https://doi.org/10.1021/cr0301144.

(30) R, N.; E, C.; JM, R.; A, M.; B, G. Mycobacterium Abscessus: A New Antibiotic Nightmare. J Antimicrob Chemother 2012, 67 (4), 810-818. https://doi.org/10.1093/JAC/DKR578.

(31) Baker, D. J.; Beddell, C. R.; Champness, J. N.; Goodford, P. J.; Norrington, F. E. A.; Smith, D. R.; Stammers, D. K. The Binding of Trimethoprim to Bacterial Dihydrofolate Reductase; 1981; Vol. 126. https://doi.org/10.1016/0014-5793(81)81030-7.

(32) Bystroff, C.; Kraut, J. Crystal Structure of Unliganded Escherichia Coli Dihydrofolate Reductase. Ligand-Induced Conformational Changes and Cooperativity in Binding. Biochemistry 1991, 30 (8), 2227-2239. https://doi.org/10.1021/bi00222a028.

(33) Hall, M. P.; Unch, J.; Binkowski, B. F.; Valley, M. P.; Butler, B. L.; Wood, M. G.; Otto, P.; Zimmerman, K.; Vidugiris, G.; MacHleidt, T.; Robers, M. B.; Benink, H. A.; Eggers, C. T.; Slater, M. R.; Meisenheimer, P. L.; Klaubert, D. H.; Fan, F.; Encell, L. P.; Wood, K. v. Engineered Luciferase Reporter from a Deep Sea Shrimp Utilizing a Novel Imidazopyrazinone Substrate. ACS Chemical Biology 2012, 7 (11), 1848-1857. https://doi.org/10.1021/cb3002478.

(34) Walker, J. R.; Hall, M. P.; Zimprich, C. A.; Robers, M. B.; Duellman, S. J.; Machleidt, T.; Rodriguez, J.; Zhou, W. Highly Potent Cell-Permeable and Impermeable NanoLuc Luciferase Inhibitors. ACS Chemical Biology 2017, 12 (4), 1028-1037. https://doi.org/10.1021/acschembio.6b01129.

(35) Savitsky, P.; Bray, J.; Cooper, C. D. O.; Marsden, B. D.; Mahajan, P.; Burgess-Brown, N. A.; Gileadi, O. High-Throughput Production of Human Proteins for Crystallization: The SGC Experience. Journal of Structural Biology 2010, 172 (1), 3-13. https://doi.org/10.1016/j.jsb.2010.06.008. 
(36) Lambert, R. J. W.; Pearson, J. Susceptibility Testing: Accurate and Reproducible Minimum Inhibitory Concentration (MIC) and Non-Inhibitory Concentration (NIC) Values. Journal of Applied Microbiology 2000, 88 (5), 784-790. https://doi.org/10.1046/j.1365-2672.2000.01017.x.

(37) Brochet, M.; Couvé, E.; Zouine, M.; Poyart, C.; Glaser, P. A Naturally Occurring Gene Amplification Leading to Sulfonamide and Trimethoprim Resistance in Streptococcus Agalactiae. Journal of Bacteriology 2008, 190 (2), 672-680. https://doi.org/10.1128/JB.01357-07.

(38) Ciruela, F. Fluorescence-Based Methods in the Study of Protein-Protein Interactions in Living Cells. Current Opinion in Biotechnology 2008, 19 (4), 338-343. https://doi.org/10.1016/j.copbio.2008.06.003.

(39) Galdiero, S.; Falanga, A.; Cantisani, M.; Tarallo, R.; Elena Della Pepa, M.; D’Oriano, V.; Galdiero, M. Microbe-Host Interactions: Structure and Role of Gram-Negative Bacterial Porins. Current Protein and Peptide Science 2013, 13 (8), 843-854. https://doi.org/10.2174/138920312804871120.

(40) Searle, M. S.; Forster, M. J.; Birdsall, B.; Roberts, G. C. K.; Feeney, J.; Cheung, H. T. A.; Kompis, I.; Geddes, A. J. Dynamics of Trimethoprim Bound to Dihydrofolate Reductase; 1988; Vol. 85. https://doi.org/10.1073/pnas.85.11.3787.

(41) Westfall, D. A.; Krishnamoorthy, G.; Wolloscheck, D.; Sarkar, R.; Zgurskaya, H. I.; Rybenkov, V. v. Bifurcation Kinetics of Drug Uptake by Gram-Negative Bacteria. PLoS ONE 2017, 12 (9), e0184671. https://doi.org/10.1371/journal.pone.0184671.

(42) Zhang, J. H.; Chung, T. D. Y.; Oldenburg, K. R. A Simple Statistical Parameter for Use in Evaluation and Validation of High Throughput Screening Assays. Journal of Biomolecular Screening 1999, 4 (2), 67-73. https://doi.org/10.1177/108705719900400206.

(43) Baba, T.; Ara, T.; Hasegawa, M.; Takai, Y.; Okumura, Y.; Baba, M.; Datsenko, K. A.; Tomita, M.; Wanner, B. L.; Mori, H. Construction of Escherichia Coli K-12 in-Frame, Single-Gene Knockout Mutants: The Keio Collection. Molecular Systems Biology 2006, 2, 2006.0008. https://doi.org/10.1038/msb4100050.

(44) Watson, M.; Liu, J. W.; Ollis, D. Directed Evolution of Trimethoprim Resistance in Escherichia Coli. FEBS Journal 2007, 274 (10), 2661-2671. https://doi.org/10.1111/j.1742-4658.2007.05801.x. 
(45) Sawaya, M. R.; Kraut, J. Loop and Subdomain Movements in the Mechanism of Escherichia Coli Dihydrofolate Reductase: Crystallographic Evidence. Biochemistry 1997, 36 (3), 586-603. https://doi.org/10.1021/bi962337c.

(46) Koronakis, V.; Eswaran, J.; Hughes, C. Structure and Function of TolC: The Bacterial Exit Duct for Proteins and Drugs. Annual Review of Biochemistry 2004, 73, 467-489. https://doi.org/10.1146/annurev.biochem.73.011303.074104.

(47) Kopytek, S. J.; Dyer, J. C. D.; Knapp, G. S.; Hu, J. C. Resistance to Methotrexate Due to AcrABDependent Export from Escherichia Coli. Antimicrobial Agents and Chemotherapy 2000, 44 (11), 3210-3212. https://doi.org/10.1128/AAC.44.11.3210-3212.2000.

(48) Sulavik, M. C.; Houseweart, C.; Cramer, C.; Jiwani, N.; Murgolo, N.; Greene, J.; DiDomenico, B.; Shaw, K. J.; Miller, G. H.; Hare, R.; Shimer, G. Antibiotic Susceptibility Profiles of Escherichia Coli Strains Lacking Multidrug Efflux Pump Genes. Antimicrobial Agents and Chemotherapy 2001, 45 (4), 1126. https://doi.org/10.1128/AAC.45.4.1126-1136.2001.

(49) Phetsang, W.; Pelingon, R.; Butler, M. S.; Kc, S.; Pitt, M. E.; Kaeslin, G.; Cooper, M. A.; Blaskovich, M. A. T. Fluorescent Trimethoprim Conjugate Probes to Assess Drug Accumulation in Wild Type and Mutant Escherichia Coli. ACS Infectious Diseases 2016, 2 (10), 688-701. https://doi.org/10.1021/acsinfecdis.6b00080.

(50) Sulavik, M. C.; Houseweart, C.; Cramer, C.; Jiwani, N.; Murgolo, N.; Greene, J.; Didomenico, B.; Shaw, K. J.; Miller, G. H.; Hare, R.; Shimer, G. Antibiotic Susceptibility Profiles of Escherichia Coli Strains Lacking Multidrug Efflux Pump Genes. Antimicrobial Agents and Chemotherapy 2001, 45 (4), 1126-1136. https://doi.org/10.1128/AAC.45.4.1126-1136.2001.

(51) Manna, M. S.; Tamer, Y. T.; Gaszek, I.; Poulides, N.; Ahmed, A.; Wang, X.; Toprak, F. C. R.; Woodard, D. R.; Koh, A. Y.; Williams, N. S.; Borek, D.; Atilgan, A. R.; Hulleman, J. D.; Atilgan, C.; Tambar, U.; Toprak, E. A Trimethoprim Derivative Impedes Antibiotic Resistance Evolution. Nature Communications 2021 12:1 2021, 12 (1), 1-10. https://doi.org/10.1038/s41467-021-23191-z.

(52) Kopytek, S. J.; Dyer, J. C. D.; Knapp, G. S.; Hu, J. C. Resistance to Methotrexate Due to AcrABDependent Export from Escherichia Coli. Antimicrobial Agents and Chemotherapy 2000, 44 (11), 3210-3212. https://doi.org/10.1128/AAC.44.11.3210-3212.2000. 
(53) Walkup, G. K.; You, Z.; Ross, P. L.; Allen, E. K. H.; Daryaee, F.; Hale, M. R.; O’Donnell, J.; Ehmann, D. E.; Schuck, V. J. A.; Buurman, E. T.; Choy, A. L.; Hajec, L.; Murphy-Benenato, K.; Marone, V.; Patey, S. A.; Grosser, L. A.; Johnstone, M.; Walker, S. G.; Tonge, P. J.; Fisher, S. L. Translating Slow-Binding Inhibition Kinetics into Cellular and in Vivo Effects. Nature Chemical Biology 2015, 11 (6), 416-423. https://doi.org/10.1038/nchembio.1796.

(54) Davoodi, S.; Daryaee, F.; Chang, A.; Walker, S. G.; Tonge, P. J. Correlating Drug-Target Residence Time and Post-Antibiotic Effect: Insight into Target Vulnerability. ACS Infectious Diseases 2020, 6 (4), 629-636. https://doi.org/10.1021/acsinfecdis.9b00484.

(55) Motulsky, H. J.; Mahan, L. C. The Kinetics of Competitive Radioligand Binding Predicted by the Law of Mass Action. Molecular Pharmacology 1984, 25 (1).

(56) Hoare, S. R. J. Analyzing Kinetic Binding Data. Assay Guidance Manual 2021.

(57) Malany, S.; Hernandez, L. M.; Smith, W. F.; Crowe, P. D.; Hoare, S. R. J. Analytical Method for Simultaneously Measuring Ex Vivo Drug Receptor Occupancy and Dissociation Rate: Application to (R)-Dimethindene Occupancy of Central Histamine H1 Receptors. http://dx.doi.org/10.1080/10799890902721339 2009, $29 \quad$ (2), $44-93$. https://doi.org/10.1080/10799890902721339.

(58) Morrison, J. F.; Walsh, C. T. The Behavior and Significance of Slow-Binding Enzyme Inhibitors. Adv Enzymol Relat Areas Mol Biol 1988, 61, 201-301. https://doi.org/10.1002/9780470123072.ch5.

(59) Brown, E. D.; Wright, G. D. Antibacterial Drug Discovery in the Resistance Era. Nature 2016, 529 (7586), 336-343. https://doi.org/10.1038/nature17042.

(60) Schenone, M.; Dančík, V.; Wagner, B. K.; Clemons, P. A. Target Identification and Mechanism of Action in Chemical Biology and Drug Discovery. Nat Chem Biol 2013, 9 (4), 232. https://doi.org/10.1038/NCHEMBIO.1199.

(61) Yuthavong, Y.; Tarnchompoo, B.; Vilaivan, T.; Chitnumsub, P.; Kamchonwongpaisan, S.; Charman, S. A.; McLennan, D. N.; White, K. L.; Vivas, L.; Bongard, E.; Thongphanchang, C.; Taweechai, S.; Vanichtanankul, J.; Rattanajak, R.; Arwon, U.; Fantauzzi, P.; Yuvaniyama, J.; Charman, W. N.; Matthews, D. Malarial Dihydrofolate Reductase as a Paradigm for Drug Development against a Resistance-Compromised Target. Proc Natl Acad Sci U S A 2012, 109 (42), 16823-16828. https://doi.org/10.1073/pnas.1204556109. 
(62) Wróbel, A.; Maliszewski, D.; Baradyn, M.; Drozdowska, D. Trimethoprim: An Old Antibacterial Drug as a Template to Search for New Targets. Synthesis, Biological Activity and Molecular Modeling Study of Novel Trimethoprim Analogs. Molecules 2020, 25 (1). https://doi.org/10.3390/molecules25010116.

(63) Cooper, C. J.; Krishnamoorthy, G.; Wolloscheck, D.; Walker, J. K.; Rybenkov, V. v.; Parks, J. M.; Zgurskaya, H. I. Molecular Properties That Define the Activities of Antibiotics in Escherichia Coli and Pseudomonas Aeruginosa. ACS Infectious Diseases 2018, 4 (8), 1223-1234. https://doi.org/10.1021/acsinfecdis.8b00036.

(64) Arrowsmith, C. H.; Audia, J. E.; Austin, C.; Baell, J.; Bennett, J.; Blagg, J.; Bountra, C.; Brennan, P. E.; Brown, P. J.; Bunnage, M. E.; Buser-Doepner, C.; Campbell, R. M.; Carter, A. J.; Cohen, P.; Copeland, R. A.; Cravatt, B.; Dahlin, J. L.; Dhanak, D.; Edwards, A. M.; Frye, S. v.; Gray, N.; Grimshaw, C. E.; Hepworth, D.; Howe, T.; Huber, K. V. M.; Jin, J.; Knapp, S.; Kotz, J. D.; Kruger, R. G.; Lowe, D.; Mader, M. M.; Marsden, B.; Mueller-Fahrnow, A.; Müller, S.; O’Hagan, R. C.; Overington, J. P.; Owen, D. R.; Rosenberg, S. H.; Roth, B.; Ross, R.; Schapira, M.; Schreiber, S. L.; Shoichet, B.; Sundström, M.; Superti-Furga, G.; Taunton, J.; Toledo-Sherman, L.; Walpole, C.; Walters, M. A.; Willson, T. M.; Workman, P.; Young, R. N.; Zuercher, W. J. The Promise and Peril of Chemical Probes. Nature Chemical Biology 2015, 11 (8), 536-541. https://doi.org/10.1038/nchembio.1867.

(65) Wróbel, A.; Arciszewska, K.; Maliszewski, D.; Drozdowska, D. Trimethoprim and Other Nonclassical Antifolates an Excellent Template for Searching Modifications of Dihydrofolate Reductase Enzyme Inhibitors. Journal of Antibiotics. 2020, pp 5-27. https://doi.org/10.1038/s41429-019-0240-6.

(66) Niederweis, M. Mycobacterial Porins - New Channel Proteins in Unique Outer Membranes. Molecular Microbiology 2003, 49 (5), 1167-1177. https://doi.org/10.1046/j.13652958.2003.03662.x.

(67) Costa-Riu, N.; Burkovski, A.; Krämer, R.; Benz, R. PorA Represents the Major Cell Wall Channel of the Gram-Positive Bacterium Corynebacterium Glutamicum. Journal of Bacteriology 2003, 185 (16), 4779-4786. https://doi.org/10.1128/JB.185.16.4779-4786.2003.

(68) Johansen, M. D.; Herrmann, J.-L.; Kremer, L. Non-Tuberculous Mycobacteria and the Rise of Mycobacterium Abscessus. Nature Reviews Microbiology 2020 18:7 2020, 18 (7), 392-407. https://doi.org/10.1038/s41579-020-0331-1. 
(69) Trias, J.; Benz, R. Permeability of the Cell Wall of Mycobacterium Smegmatis. Molecular Microbiology 1994, 14 (2), 283-290. https://doi.org/10.1111/j.1365-2958.1994.tb01289.x.

(70) Coussens, N. P.; Auld, D.; Roby, P.; Walsh, J.; Baell, J. B.; Kales, S.; Hadian, K.; Dahlin, J. L. CompoundMediated Assay Interferences in Homogeneous Proximity Assays. Assay Guidance Manual 2020.

(71) Av-Gay, Y.; Everett, M. The Eukaryotic-like Ser/Thr Protein Kinases of Mycobacterium Tuberculosis. Trends in Microbiology 2000, 8 (5), 238-244. https://doi.org/10.1016/S0966-842X(00)01734-0.

(72) Fraga, H.; Rodriguez, B.; Bardera, A.; Cid, C.; Akopian, T.; Kandror, O.; Park, A.; Colmenarejo, G.; Lelievre, J.; Goldberg, A. Development of High Throughput Screening Methods for Inhibitors of ClpC1P1P2 from Mycobacteria Tuberculosis. Analytical Biochemistry 2019, 567, 30-37. https://doi.org/10.1016/j.ab.2018.12.004.

(73) Moreira, W.; Santhanakrishnan, S.; Ngan, G. J. Y.; Low, C. B.; Sangthongpitag, K.; Poulsen, A.; Dymock, B. W.; Dick, T. Towards Selective Mycobacterial ClpP1P2 Inhibitors with Reduced Activity against the Human Proteasome. Antimicrobial Agents and Chemotherapy 2017, 61 (5), e02307-16. https://doi.org/10.1128/AAC.02307-16.

(74) Guzman, L. M.; Belin, D.; Carson, M. J.; Beckwith, J. Tight Regulation, Modulation, and High-Level Expression by Vectors Containing the Arabinose P(BAD) Promoter. Journal of Bacteriology 1995, 177 (14), 4121-4130. https://doi.org/10.1128/jb.177.14.4121-4130.1995.

(75) Andreu, N.; Zelmer, A.; Fletcher, T.; Elkington, P. T.; Ward, T. H.; Ripoll, J.; Parish, T.; Bancroft, G. J.; Schaible, U.; Robertson, B. D.; Wiles, S. Optimisation of Bioluminescent Reporters for Use with Mycobacteria. PLOS ONE 2010, 5 (5), e10777. https://doi.org/10.1371/JOURNAL.PONE.0010777.

(76) Yung-Chi, C.; Prusoff, W. H. Relationship between the Inhibition Constant (KI) and the Concentration of Inhibitor Which Causes 50 per Cent Inhibition (150) of an Enzymatic Reaction. Biochemical Pharmacology 1973, 22 (23), 3099-3108. https://doi.org/10.1016/00062952(73)90196-2.

(77) Rashid, U.; Ahmad, W.; Hassan, S. F.; Qureshi, N. A.; Niaz, B.; Muhammad, B.; Imdad, S.; Sajid, M. Design, Synthesis, Antibacterial Activity and Docking Study of Some New Trimethoprim Derivatives. Bioorganic \& Medicinal Chemistry Letters 2016, 26 (23), 5749-5753. https://doi.org/https://doi.org/10.1016/j.bmcl.2016.10.051. 


\section{Supplementary Files}

This is a list of supplementary files associated with this preprint. Click to download.

- 20220609FantiSIfinalpreprint.pdf 